\title{
SHOCK COMPRESSION OF MOLTEN SILICATE: RESULTS FOR A MODEL BASALTIC COMPOSITION
}

\author{
S. M. Rigden ${ }^{1}$, Thomas J. Ahrens, and E. M. Stolper
}

Seismological Laboratory, California Institute of Technology, Pasadena

\begin{abstract}
A technique has been developed for measurement of the shock wave, pressure-density equation of state of molten silicates initially at temperatures of $\mathrm{up}$ to $\sim 2000$ K. A $40-\mathrm{mm}$ propellant gun apparatus accelerates metal flyer plates to speeds of up to $2.5 \mathrm{~km} \mathrm{~s}^{-1}$; these flyer plates are capable of driving shock waves with amplitudes of 35$40 \mathrm{GPa}$ (350-400 kbar) into molten silicate samples. Modifications to the standard equation of state experiments that are described here include design of a molybdenum sample container for the molten silicate; use of a $10-\mathrm{kW}$ radio frequency induction heater to melt the sample prior to impact; implementation of shuttering systems to protect the optical system and prevent preexposure of the film in the rotating-mirror, continuously writing, streak camera; and reduction of Hugoniot data taking into account the effect of the sample capsule. Data for a model basaltic liquid (36 mol \% anorthite, $64 \mathrm{~mol} \%$ diopside) at an initial temperature of $1673 \mathrm{~K}$ and initial density of $2.61 \mathrm{Mg} \mathrm{m}^{-3}$, yield a shock velocity-particle velocity $\left(U_{S}-U_{P}\right)$ relation given by $\mathrm{U}_{\mathrm{S}}=3.06+1.36 \mathrm{U}_{\mathrm{P}} \mathrm{km} \mathrm{s}^{-1}$ up to values of $\mathrm{U}_{\mathrm{P}}=1.7 \mathrm{~km} \mathrm{~s}^{-1}$. The zero-pressure, bulk sound speed is in good agreement with ultrasonic measurements. The best fit Birch-Murnaghan equation of state for this model basaltic liquid is $\mathrm{K}_{0 \mathrm{~S}}=24.2 \mathrm{GPa}$ and $\mathrm{K}^{\prime}=4.85$ based on Hugoniot points at low pressures $(<25 \mathrm{GPa})$. Within the resolution of our data set, density increases smoothly with pressure over the 0-25 GPa pressure range, suggesting that structural rearrangements take place gradually in response to pressure in this pressure interval. At high pressures $(2$ $25 \mathrm{GPa}$ ) the Hugoniot data suggest that the liquid stiffens considerably. This may indicate that the gradual structural changes characteristic of the lower-pressure regime, such as changes of $\mathrm{Al}^{3+}$ and $\mathrm{Si}^{4+}$ coordination by oxygen from fourfold to sixfold, are essentially complete by $\sim 25$ GPa. These high-pressure Hugoniot data are fit by $\mathrm{U}_{\mathrm{S}}=0.85+2.63 \mathrm{U}_{\mathrm{P}} \mathrm{km} \mathrm{s}^{-1}$. The high-pressure regime is similar to that obtained in initially solid silicates upon shock compression. Shock temperature calculations yield values of $2400-2600 \mathrm{~K}$ at $25 \mathrm{GPa}$, and the states achieved are believed to lie metastably in the liquid field.
\end{abstract}

\section{Introduction}

The density of a silicate melt (or indeed, of any substance) is one of its most fundamental physical properties. The pressure-density-temperature relation, or equation of state, along with the heat capacity, provides a description of thermodynamic properties that can be applied to modeling and interpreting solid-liquid phase equilibria critical to understanding igneous petrogenesis. The density is also an expression of the liquid's in tegrated microscopic structure; thus systematic study of density can yield insights into melt structure and provide a framework for describing physical properties (e.g., viscosity, diffusivities) that play critical roles in planetary evolution and petrogenesis. Finally,

${ }^{1}$ Now at Research School of Earth Sciences, Australian National University, Canberra.

Copyright 1988 by the American Geophysical Union.

Paper number 6B6294.

0148-0227/88/006B-6294\$05.00 and perhaps most directly relevant to igneous processes, the density contrast between liquids and crystalline solids plays a crucial role in determining the directions and velocities of magma transport within the Earth and other planets, and thus knowledge of the densities of melts at conditions relevant to planetary interiors is fundamental to understanding igneous activity and planetary differentiation.

The systematics of the densities of silicate melts at atmospheric pressure are well known (see, for example, Bottinga and Weill [1970], Nelson and Carmichael [1979], Mo et al. [1982], and Bottinga et al. [1982]), but little was known until recently about melt densities at elevated pressures. Although there have been calculations and inferences of silicate melt density at high pressure based on measured elastic properties of melts at low pressure [Stolper et al., 1981; Nisbet and Walker, 1982], on molecular dynamics simulations [Woodcock et al., 1976; Angell et al., 1982, 1983, 1986; Matsui and Kawamura, 1980, 1984; Matsui et al., 1982], and on analysis of the solidi of congruently melting minerals [Ohtani, 1984; Bottinga, 1985; Rivers, 1985], there have been [ew actual measurements of silicate melt densities at elevated pressure. Until recently, the "falling sphere" technique was the only way such measurements were made [Kushiro, 1978, 1980; Fujii and Kushiro, 1977; Scarfe et al., 1979; Sharpe et al., 1983]. However, measurements using this technique have been restricted to less than $3 \mathrm{GPa}$, and the accuracy of highpressure densities based on it is questionable [Rivers, 1985].

Shock wave techniques are routinely used for accurate determination of density as a function of pressure along the Hugoniot for solids [e.g., McQueen et al., 1967, 1970]. Pressures in excess of $400 \mathrm{GPa}$ have been achieved using these techniques [Al'tshuler, 1965]. In this paper, we describe a set of experiments in which we have used shock wave techniques to study the density of a model basaltic liquid at pressures between 4 and $35 \mathrm{GPa}$. Preliminary results and a discussion of their implications have been presented elsewhere [Rigden et al., 1984]. The focus of this paper will be on the experimental techniques that we have utilized and, in particular, on the modifications to the "standard" shock wave techniques developed for use on cool solids that were necessary in order for us to carry out these experiments on molten samples.

In a typical shock wave experiment, a high-pressure pulse is generated in a cool solid sample by high-velocity impact of a metal plate. Measurement of the velocity of the high-pressure shock wave and the particle velocity in the sample enables the pressure and density to be calculated via the Rankine-Hugoniot equations. The extraordinary problem that we faced in our experiments was basically this: How do you get the target hot enough so that it is molten prior to impact by the projectile and so that the material whose equation of state is being studied is liquid rather than solid? The solution that we chose was to encapsulate the material in a metallic container, which we then heated by induction. This solution created its own set of problems; for example, how do you hold the capsule? how do you measure the initial temperature? how do you correct the shock velocity for the presence of the metal capsule? In this paper, we describe how we dealt with these and other problems unique to high-temperature shock wave experiments and their data reduction and present the complete data set on the first liquid silicate that we have studied. 


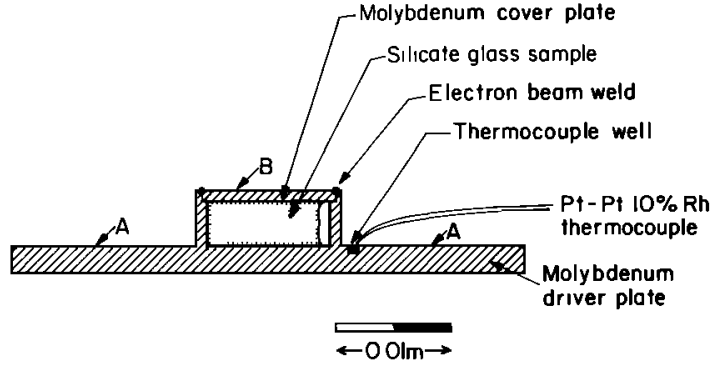

Fig. 1. Schematic cross section through the molybdenum/sllicate sample assembly. The base is constructed in one piece, and a thin $(0.75 \mathrm{~mm})$ cap is welded onto the base using an electron beam welding technique. Surfaces $A$ and $B$ are polished to a mirror finish. Light reflected from these polished surfaces during the course of the experiment is detected by a streak camera. A Pt$\mathrm{Pt10 \% \textrm {Rh }}$ thermocouple is pressed into the driver plate (surface A) close to the top of the sample.

\section{Sample Preparation}

\section{Sample Container}

In contrast to a standard equation of state experiment where a solid target sample is mounted on a metal driver plate, the sample in this experiment, molten at the time of impact, is totally enclosed in a metal container. If the sample is not completely enclosed, it leaks out of the container upon melting. The sample capsule is constructed of molybdenum (ABL low-carbon, vacuum arc-cast molybdenum supplied by AMAX Specialty Metals). The 1-atm melting point of molybdenum $(2890 \mathrm{~K})$ is higher than that of any likely silicate sample, a primary consideration in its choice.

The sample container/driver plate assembly is shown schematically in Figure 1. The glass sample is sealed in the capsule by electron beam welding a thin $(0.75 \mathrm{~mm})$ molybdenum cap onto its cylindrical walls. During the welding process, the molybdenum capsule must be treated carefully to prevent cracking because the metal is extremely brittle. Initially, the assembly is preheated to red heat for several minutes. This degasses the join where the weld is made and releases volatiles from pore space in the molybdenum. After welding, the capsule is cooled slowly under a broad electron beam to anneal the weld. During cooling, an observation of the weld at $800-900 \mathrm{~K}$ is made to ensure that it is free from cracks. The welded target is finally heated to $1673 \mathrm{~K}$ in a mufle furnace for about 1 hour under $1 \mathrm{~atm}$ of nitrogen. This step premelts the sample so that it wets the sides of the container and ensures that the capsule is completely sealed; at this stage the sample will leak out if any cracks are present in the weld. In addition, it is important that the molten sample be free from bubbles because the path of the shock wave should be uninterrupted. Sample containers crosssectioned after this heating procedure contained clear, bubble-free glass.

\section{Silicate Sample}

Several criteria were used to choose the sample material: (1) The sample should be of geological or geophysical relevance. (2) Because the presence of bubbles would interfere with travel of the shock wave through the sample, the viscosity must be low enough that bubbles will rise buoyantly to the top of the container during the premelting procedure. If the sample viscosity is $<100 \mathrm{P}$, bubbles $>50 \mu \mathrm{m}$ in diameter should be unable to remain suspended for longer than $\sim 5$ min. (3) The molybdenum sample container undergoes oxidation at a rate strongly dependent on its temperature under the vacuum conditions in the impact $\operatorname{tank}(\sim 100 \mu \mathrm{m} \mathrm{Hg})$, so the melting tempera- ture of the silicate sample must be relatively low. Otherwise, oxides are ejected from the hot molybdenum and deposited on nearby unheated or cooler surfaces. These deposits can interfere with the optical path to the recording camera. In addition, the higher the temperature of the sample container, the more strain is placed on ceramic pieces that hold it in place.

The composition chosen for the experiments described in this paper is that of the 1-atm eutectic in the system anorthite-diopside. This composition satisfies the criteria of low melting point (1547 K, [Bowen, 1915] and low viscosity $(\sim 30 \mathrm{P}$ at $1673 \mathrm{~K}$ [Bottinga and Weill, 1972]). The ideal chemical composition of the sample $(64 \mathrm{~mol} \%$ $\left.\mathrm{CaMgSi}_{2} \mathrm{O}_{6} ; 36 \mathrm{~mol} \% \mathrm{CaAl}_{2} \mathrm{Si}_{2} \mathrm{O}_{8}\right)$ is given in Table 1 . This is a compositional analog for natural basalt. The anorthite-diopside eutectic composition differs from actual basalts in its absence of iron and alkalis and its excess of calcium. The composition of average Mid-Atlantic Ridge (MAR) basalt [Melson and Thompson, 1971] is shown in Table 1 for comparison.

Samples are prepared from spectroscopically pure oxides $\left(\mathrm{SiO}_{2}, \mathrm{MgO}, \mathrm{Al}_{2} \mathrm{O}_{3}\right)$ and $\mathrm{CaCO}_{3}$. The chemicals are weighed out in the appropriate proportions to make $5 \mathrm{~g}$ of sample and ground for 5 hours in an agate mortar under alcohol to produce a homogeneous powder. This powder is then heated in a $\mathrm{Pt}$ crucible in a muffle furnace at $1673 \mathrm{~K}$ for several hours to melt the sample and drive off $\mathrm{CO}_{2}$. Upon removal from the furnace a colorless glass that may have many bubbles is produced. To remove bubbles and any volatiles contained in the glass, a second melting is undertaken in a vacuum furnace under air pressure of less than $100 \mu \mathrm{m} \mathrm{Hg}$ at $1673 \mathrm{~K}$. This second melting stage lasts about 12 hours and yields a clear, bubble-free glass. The average composition from several such runs, measured with the electron microprobe, is shown in Table 1 and agrees well with the ideal composition. The glass sample is removed from the $\mathrm{Pt}$ crucible with a diamond core drill. It is then ground to fit into the molybdenum container and welded as described above.

\section{Experimental Method}

A shock wave is generated in the sample by impact of a metal flyer plate embedded in a lexan projectile. The pressure and density in the high-pressure shocked state are determined by application of the Rankine-Hugoniot conservation equations:

TABLE 1. Sample and Natural Basalt Compositions

\begin{tabular}{lccr}
\hline & $\begin{array}{c}\text { Average of Eight } \\
\text { Analyses, } \\
\text { wt \% }\end{array}$ & $\begin{array}{c}\text { Ideal } \\
\text { Composition } \\
\text { wt \% }\end{array}$ & $\begin{array}{c}\text { Average MAR } \\
\text { Basalt, } \\
\text { wt \% }\end{array}$ \\
\hline $\mathrm{SiO}_{2}$ & $50.5 \pm 0.5$ & 50.34 & 49.21 \\
$\mathrm{TiO}_{2}$ & $15.4 \pm 0.8$ & 15.38 & 1.39 \\
$\mathrm{Al}_{2} \mathrm{O}_{3}$ & & & 15.81 \\
$\mathrm{FeO}$ & & 10.80 & 9.18 \\
$\mathrm{MnO}$ & $10.5 \pm 1.0$ & 23.48 & 0.16 \\
$\mathrm{MgO}$ & $23.9 \pm 0.3$ & & 11.14 \\
$\mathrm{CaO}$ & & & 2.71 \\
$\mathrm{Na}_{2} \mathrm{O}$ & & & 0.26 \\
$\mathrm{~K}_{2} \mathrm{O}$ & & & 0.15 \\
$\mathrm{P}_{2} \mathrm{O}_{5}$ & & & 100.00 \\
$\mathrm{Total}$ & 100.3 & & 100.54 \\
\hline
\end{tabular}

a Analyzed by electron microprobe.

b Average Mid-Atlantic Ridge basalt [Melson and Thompson, 1971]. 


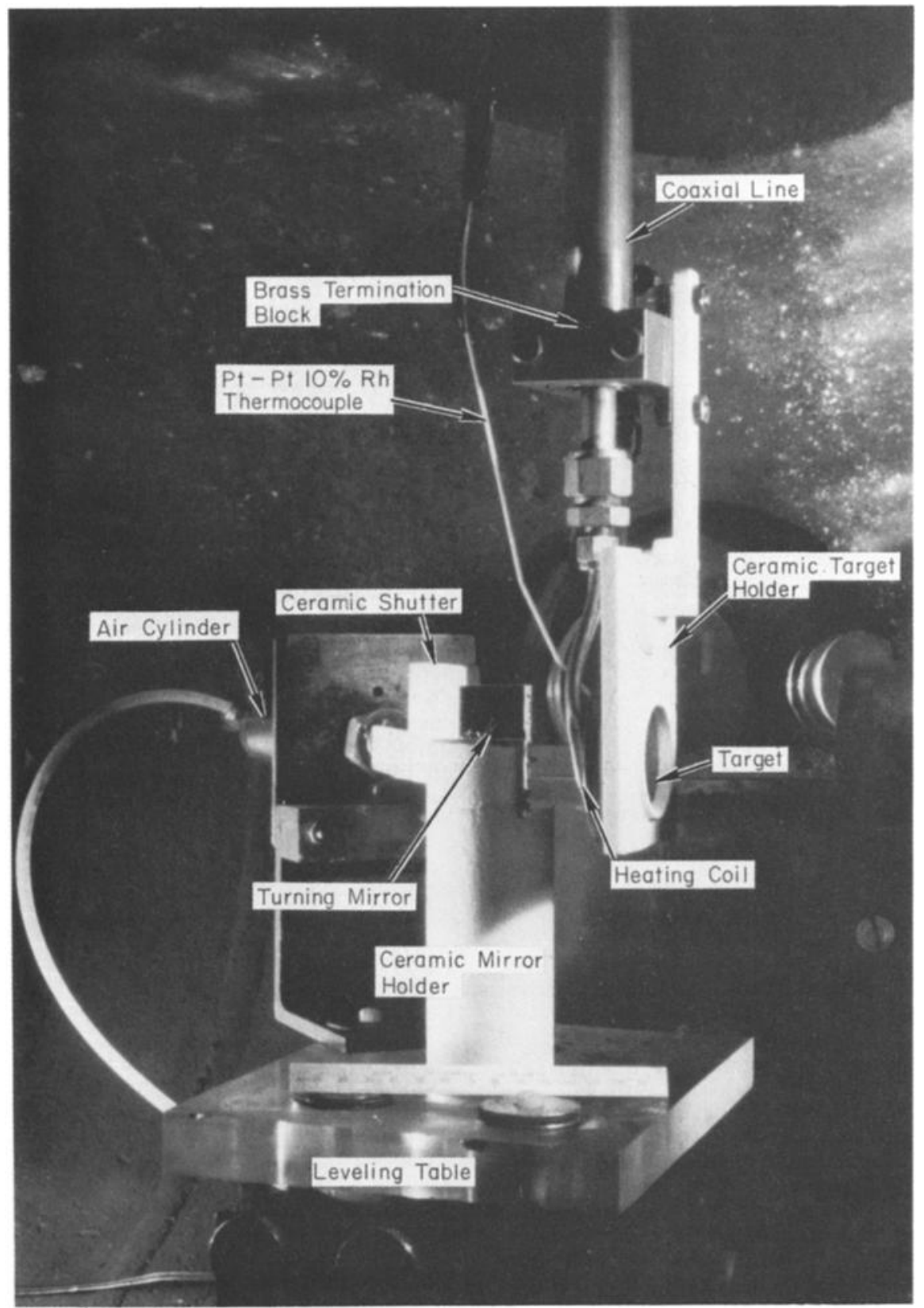

Fig. 2. Photograph of a sample assembly in the impact tank. The brass termination block of the copper coaxial cable is used to hold the ceramic target plate. The sample assembly is aligned with the barrel of the gun (visible at far right). The copper heating coil, sheathed thermocouple, and turning mirror mounted on a ceramic pedestal are visible behind the sample. A ceramic shutter protects the mirror until just before the shot is fired.

$$
\begin{gathered}
\mathrm{P}=\rho_{0 \mathrm{~S}} \mathrm{U}_{\mathrm{SS}} \mathrm{U}_{\mathrm{PS}} \\
\rho=\rho_{0 \mathrm{~S}} \mathrm{U}_{\mathrm{SS}} /\left(\mathrm{U}_{\mathrm{SS}}-\mathrm{U}_{\mathrm{PS}}\right)
\end{gathered}
$$

Here, $\rho_{0 S}$, the 1-atm density of the molten sample, is calculated using the measured temperature and the partial molar volumes of the constituent oxides given by Stebbins et al. [1984]. $U_{S S}$ and $U_{P S}$ are the shock and particle velocities in the molten silicate; these are determined from shock transit time through the sample and the measured projectile velocity. Measured quantities for this experiment are sample shock transit time and projectile velocity from which $U_{S S}$ and $U_{P S}$ are calculated and the initial sample temperature from which $\rho_{0 S}$ is determined. The projectile is launched from a $40-\mathrm{mm}$ bore propellant gun described by Ahrens et al. [1971]. The front portion of the sample capsule serves as the shock driver plate (Figure 1). This target is mounted in a Zircar fibrous alumina ceramic plate (type ZAL-45) and suspended in the impact tank (Figure 2).

\section{Heating and Sample Geometry}

Heating is accomplished by a water-cooled copper induction coil powered by a $10-\mathrm{kW}$ Lepel radio frequency generator (model T-10-3-KC-N-W). The $10-\mathrm{kW}$ maximum output of the generator is ample to heat the molybdenum sample assembly. For example, the energy required to heat 


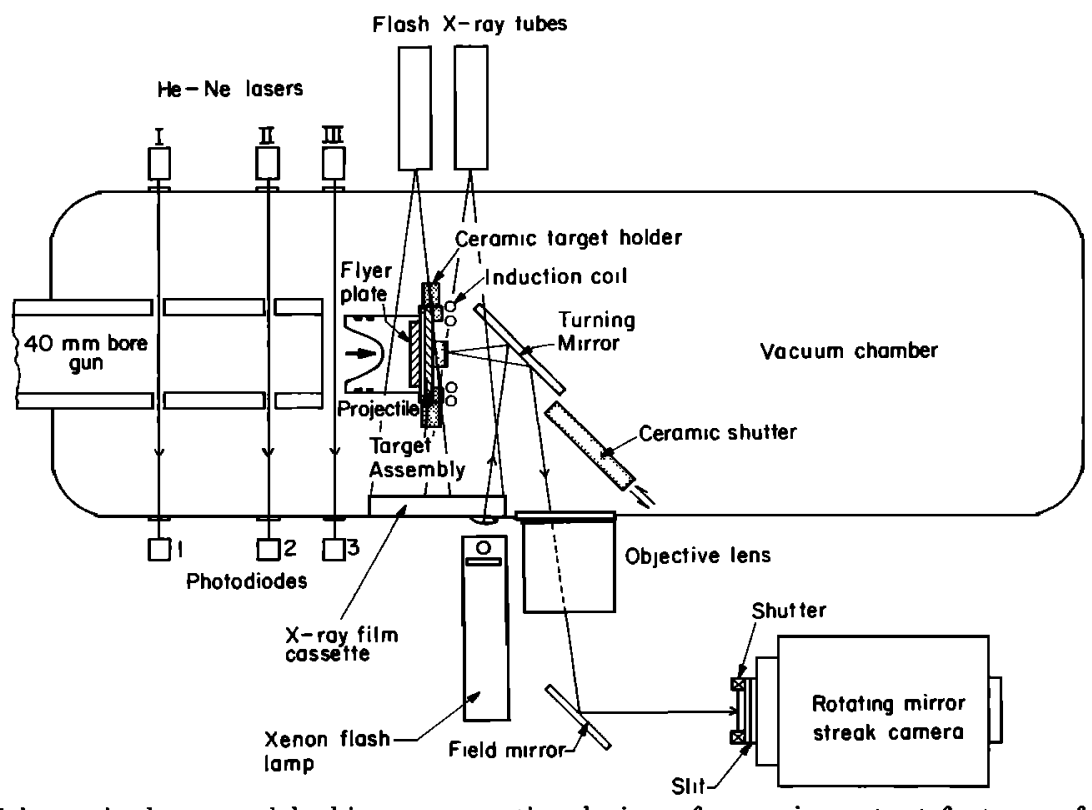

Fig. 3. Schematic downward looking cross-sectional view of some important features of the molten silicate equation of state experiment. Three lasers (I, II, and III) across the barrel are used to initiate trigger signals to $\mathrm{X}$ ray source and xenon flash lamp. The double flash $\mathrm{X}$ ray sources form a dual image of the projectile enroute to the target on $\mathrm{x}$-ray film; this is used to calculate the projectile velocity and also shows whether target movement has occurred during heating. A second estimate of projectile velocity is made by recording travel times between lasers I, II, and III. A turning mirror mounted on a ceramic pedestal behind the target is protected during sample heating by a ceramic shutter; this is withdrawn immediately prior to firing the gun. The xenon flash lamp illuminates the target; light is focused onto the target and reflected from the polished rear surfaces of the sample assembly via the turning mirror, a $305-\mathrm{mm}$, f 2.5 Kodak Aero-Ektar objective lens and field mirror to the streak camera.

a typical sample assembly $(33 \mathrm{~g})$ to $1800 \mathrm{~K}$ is about $15 \mathrm{~kJ}$, or $1.5 \mathrm{~s}$ of operation at the peak output of the RF generator. Radiant losses (by blackbody radiation) in the vacuum conditions of the experiment at this temperature amount to approximately $2 \mathrm{~kW}$. Thus the present apparatus has ample power to attain and maintain the high temperature necessary for this experiment. To minimize electromagnetic radiative losses of high-frequency $(250-450 \mathrm{kHz})$ energy, a coaxial line is utilized from the generator to within $12 \mathrm{~cm}$ of the load coil. A 12:1 stepdown transformer (model LCT-4) is inserted in the coaxial line immediately before the line enters the vacuum tank. Without this transformer, the high voltage leads to arcing across the load coil under the poor vacuum $(\sim 100 \mu \mathrm{m} \mathrm{Hg})$ conditions in the tank. When the coaxial line was not extended close to the coil, approximately $80 \%$ of the available RF energy was lost between the transformer and load coil (a distance of $50 \mathrm{~cm}$ ).

Within the tank, the coaxial line doubles as a support system for the target assembly and water-cooling system (0.7 $\mathrm{L} \mathrm{s}^{-1}$, flow rate). The target assembly is attached to the brass termination block of the coaxial line. A hollowcentered pie-shaped induction coil is used because of space constraints and to preserve an optical path from the sample to the recording streak camera. This coil is positioned behind the target assembly with its center on line with the center of the sample. A Pt-Pt10\%Rh thermocouple (0.25mm-thick wire), pressed into a $1.6-\mathrm{mm}$-diameter, $1.0-\mathrm{mm}$ deep well in the driver plate just above the sample (Figure 2), monitors the temperature until the gun is fired. Behind the coil and sample assembly, a turning mirror reflects the image of the sample through a window in the impact tank via a system of lenses and mirrors to a continuously writing Beckman-Whitley streak camera (model 339). This turning mirror is mounted on a Zircar fibrous alumina ceramic cylinder (type ALC) attached to a leveling table. Under the vacuum conditions in the impact tank, molybdenum undergoes rapid oxidation at high temperatures. An alumina ceramic shutter (Zircar type ZAL-45) covers the mirror until the shot is fired. This protects the mirror from the energy radiated by the sample and also shields it from the stream of molybdenum oxides deposited on cool surfaces around the heated sample assembly. The shutter is retracted with a double-acting Bimba (model SSRD-173DNR-B) air cylinder operating under a pressure of 1.5 bars approximately $1 \mathrm{~s}$ before impact of the flyer plate on the driver plate; this allows a clear optical path to the streak camera. Air lines external to the tank control the air cylinder.

\section{Measurement of Shock Transit Time}

The shock transit time through the sample plus molybdenum cover plate is measured by observing the sample assembly rear surfaces via the streak camera. Both the driver plate rear surface and that of the molybdenum cover plate (Figure 1) are polished to a mirror finish. A xenon flash lamp [Goto et al., 1979], triggered by passage of the projectile past laser I (Figure 3), illuminates the sample. As the shock wave traverses the polished surfaces, a change in reflectivity is detected by the streak camera (Figure 4a). An actual streak record is shown in Figure $4 \mathrm{~b}$. The slit in the streak camera field of view is horizontal and hence avoids the meniscus of molten silicate shown in Figure 1.

In a standard equation of state experiment, the streak camera shutter is opened before the firing circuit of the gun is completed. Completion of the firing circuit requires that both the camera shutter be held open and the propellant gun be fired within 1-2 s. In this experiment the camera shutter is opened by a solenoid $2 \mathrm{~ms}$ after the gun firing mechanism is activated. This is necessary because light from the hot, radiating sample would otherwise fog the film and obscure the streak record. Although the light intensity from the radiating sample is far lower than from the single $100-\mu \mathrm{s}$ duration xenon flash, the film can be overwritten several thousand times in the 1-2 $\mathrm{s}$ delay between opening the shutter and turning the firing key. A single sweep of the film in the streak camera occurs in $\sim 250 \mu$ s. 


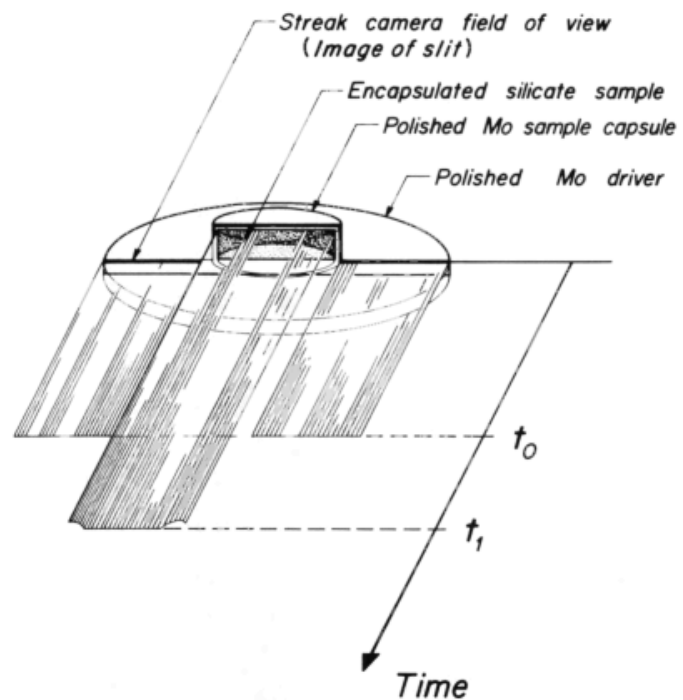

Fig. 4a. Streak record from molten silicate shock wave experiment. Cutaway view of the sample. Before passage of the shock wave through the reflective surfaces, light is reflected continuously from the rear of the sample. A change of reflectivity as the shock wave exits the metal driver plate (at the same time entering the sample) is detected by the streak camera. A similar change occurs as the shock wave exits the sample assembly. An idealized streak record is superimposed on the sample cutaway view.

\section{Measurement of the Projectile Velocity}

The projectile velocity is measured by two techniques. The first involves measuring the time taken for the projectile to travel between three lasers that cross the flight path and are a known distance apart (Figure 3 ). This measurement is made in the last $0.70 \mathrm{~m}$ of the $20-\mathrm{m}$ projectile travel. As the projectile crosses the first 2-mW He-Ne laser, a voltage increase is detected by a PIN photodiode (Hewlett-Packard, 5082-4220) in line with the laser. This triggers an electronic counting system. Passage of the projectile across the second and third lasers gives time intervals to within $0.01 \mu \mathrm{s}$, which, in principle, allows the projectile velocity to be calculated with a precision of $0.2 \%$ at the highest velocities. However, nonreproducible projectile slowing via friction can degrade this precision.

The second method of measuring projectile velocity utilizes dual-flash $\mathrm{X}$ ray sources. Two Hewlett-Packard, Field Emission Type 526 Flash $X$ ray tubes illuminate a 12 x $24 \mathrm{~mm}$ cassette containing Kodak type X-OMAT AR, X ray film with a Dupont Quanta $3 X$ ray intensifier screen. This occurs within the last $5 \mathrm{~cm}$ of projectile travel. A 30 ns duration $30-\mathrm{kV} \mathrm{X}$ ray pulse is triggered when the projectile crosses the third laser, and the second flash $X$ ray is activated after a time interval dependent on the expected projectile velocity. Measurement of the separation of the two images of the projectile on the $X$ ray film enables determination of the projectile velocity. The $X$ ray shadowgraph is also used to check the integrity and orientation of the projectile/flyer assembly. Figure 5 shows a typical $\mathrm{X}$ ray shadowgraph for the molten silicate equation of state experiment.

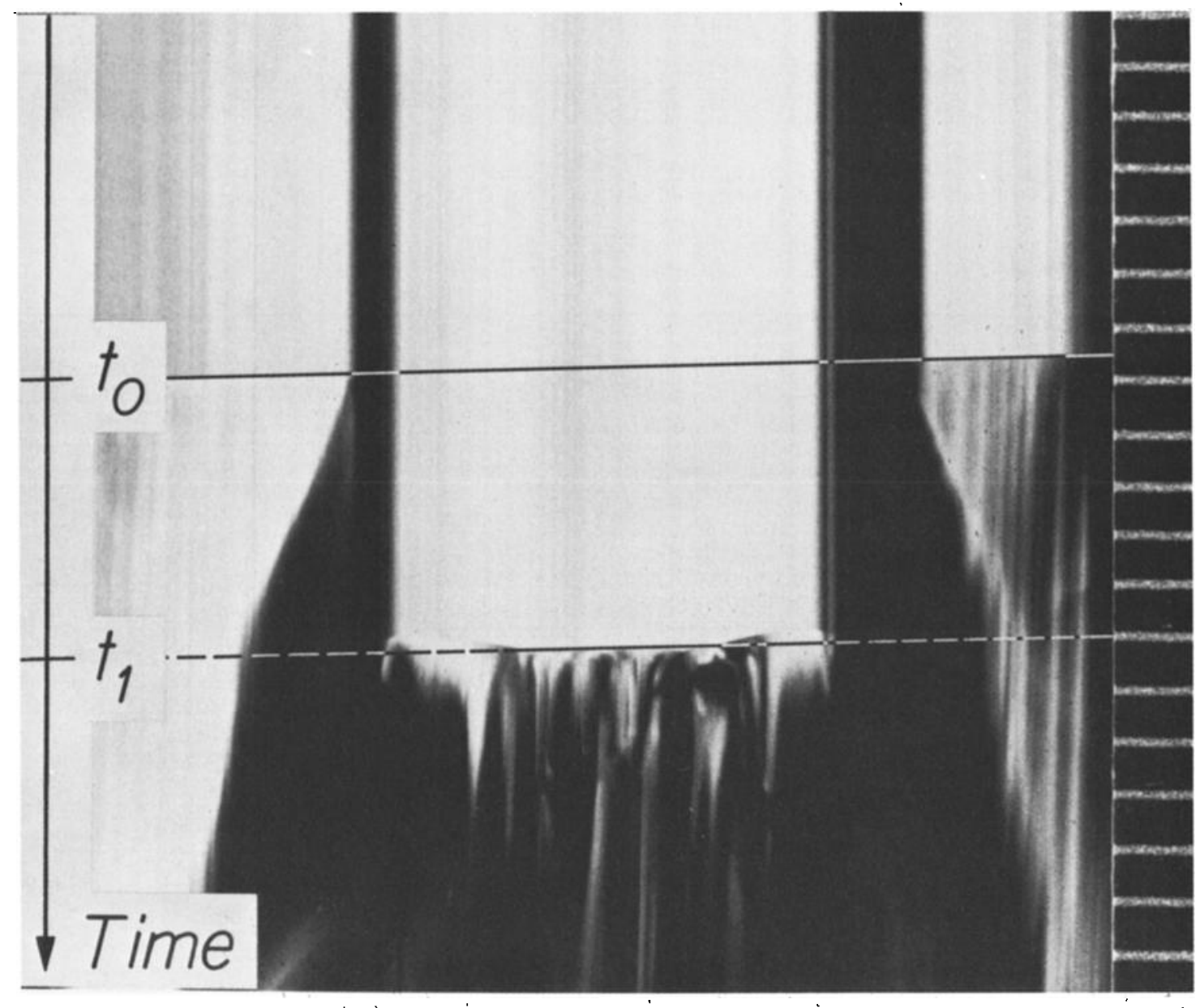

Fig. 4b. An actual streak recórd from a typical experiment (shot 607). The time $\left(t_{1}-t_{0}\right)$ represents the transit time of the shock wave through the silicate sample and molybdenum cover plate. 


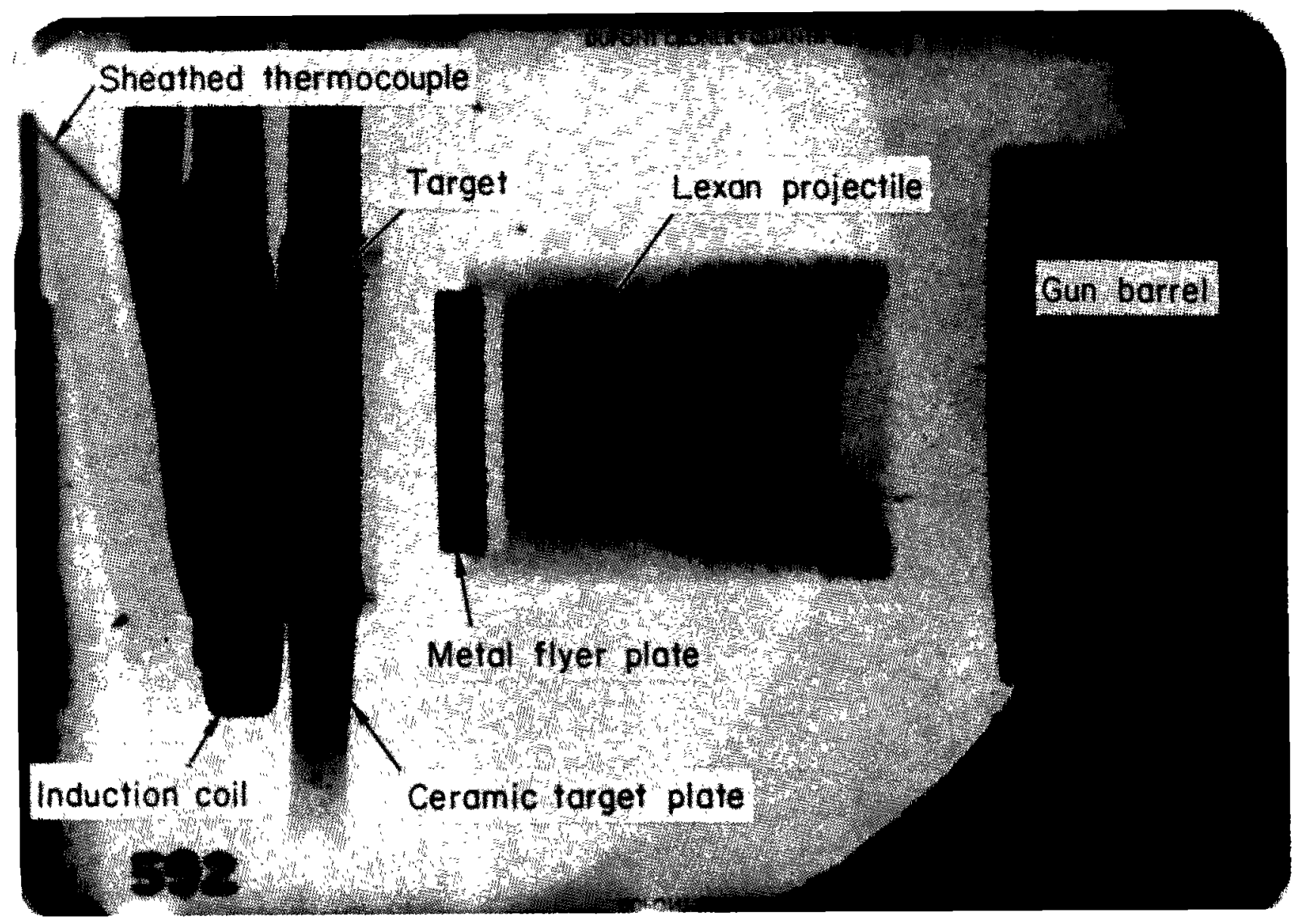

Fig. 5. X ray shadowgraph of typical molten silicate equation of state experiment used to measure projectile velocity (shot 592). The shadowgraph shows a double exposure of the projectile carrying a metal fyer plate during its fight toward the sample. The target assembly can also be seen. Shadow images of the sample, coil, mirror, and thermocouple are visible to the left of the projectle.

The calculated velocity ( $\mathrm{U}_{\mathrm{imp}}$ in $\mathrm{mm} \mu \mathrm{s}^{-1}$ ) of the projectile from the $\mathrm{X}$ ray shadowgraph is given by

$$
\mathrm{U}_{\mathrm{imp}}=\frac{l+\delta}{\mathrm{M}(\Delta \mathrm{t})}
$$

where $l$ is the measured distance between images on the fim (in millimeters), $\delta$ is the parallax (separation for a stationary target in millimeters), $M$ is the film magnification, and $\Delta t$ is the delay time (in microseconds) between firing the two $\mathrm{X}$ ray tubes. For the range of possible projectile velocities $\left(\sim 1\right.$ to $\left.2.5 \mathrm{~km} \mathrm{~s}^{-1}\right), l$ ranges from about 27 to 16 $\mathrm{mm}$. The uncertainty in the measurement of this distance results in an uncertainty of about $2 \%$ in the projectile velocity. This second method of measuring projectile velocity is preferred and is the source of the values given in Table 2 because it gives a velocity closest to the target. As discussed above, the first method, although more precise for a given time interval, needs to be corrected for slowing during the last meter of projectile travel and provides a backup measure of projectile velocity. If a slowing correction is made, the two measurements are usually in good agreement.

\section{Capsule Equation of State}

In a standard equation of state experiment the shock velocity is calculated directly from the transit time through the sample. Using the measured projectile velocity, the shock pressure and particle velocity can then be derived by impedance match [e.g., Rice et al., 1958]. In the present experiment the shock velocity is not directly calculable from the observed shock transit time because the measured transit time on the streak record gives the travel time of the shock through both the 4-mm-thick sample and the $0.75-\mathrm{mm}$-thick molybdenum cover plate. The shock equation of state of the molybdenum capsule must thus be known before the shock and particle velocities for the sample can be calculated. Although the shock equation of state of molybdenum has been measured starting at room temperature [Marsh, 1980], there are no experimental data on the high-temperature Hugoniot We have made a single determination of the shock equation of state of molybdenum at an initial temperature of $1273 \mathrm{~K}$, with a pure molybdenum target heated using the induction coil assembly previously described. The result of this experiment is shown in the $\mathrm{P}-\mathrm{U}_{\mathrm{P}}$ plane in Figure 6.

For comparison with our experimental determination, we have also calculated the Hugon ot of molybdenum initially at $1273 \mathrm{~K}$ (Figure 6 ). In calculating th is Hugoniot, a Mie-Gruneisen equation of state was assumed. For two Hugoniot states at constant volume $\mathrm{V}$ but different initial densities, the difference in pressure $\Delta \mathrm{P}$ is given by

$$
\Delta \mathrm{P}=\Delta \mathrm{E} \gamma / \mathrm{V}
$$

where $\gamma$ is Gruneisen's parameter and $\Delta \mathrm{E}$ is the internal energy difference. Using the expressions for the energy of the two Hugoniot states from the Rankine-Hugoniot equatiun for conservation of energy and taking in to account the energy difference between an initial state at room temperature $T_{C}$ and high temperature $T$, the following expression can be derived: 
TABLE 2. Molten $\mathrm{An}_{\mathbf{0 . 3 6}} \mathrm{Di}_{\mathbf{0 . 6 4}}$ Hugoniot Data

\begin{tabular}{|c|c|c|c|c|c|c|}
\hline Shot & $\begin{array}{l}\text { Flyer } \\
\text { Plate }\end{array}$ & $\begin{array}{c}\text { Impact } \\
\text { Velocity }^{\mathbf{2}} \\
\mathrm{km} \mathrm{s}^{-\mathrm{Z}}\end{array}$ & $\begin{array}{c}\text { Shock } \\
\text { Velocity, } \\
\text { km s}^{-1}\end{array}$ & $\begin{array}{c}\text { Particle } \\
\text { Velocity, } \\
\mathrm{km} \mathrm{s}^{-1}\end{array}$ & $\begin{array}{c}\text { Hugoniot } \\
\text { Pressure, } \\
\text { GPa }\end{array}$ & $\begin{array}{c}\text { Hugoniot } \\
\text { Density } \\
\text { Mg m}^{-3}\end{array}$ \\
\hline 592 & $\mathrm{Al}$ & $\begin{array}{r}1.05 \\
\pm 0.03\end{array}$ & $\begin{array}{r}375 \\
\pm 0.06\end{array}$ & $\begin{array}{r}0.44 \\
\pm 0.02\end{array}$ & $\begin{array}{r}4.3 \\
\pm 0.2\end{array}$ & $\begin{array}{r}2.95 \\
\pm 0.03\end{array}$ \\
\hline 593 & $\mathrm{Al}$ & $\begin{array}{r}1.50 \\
\pm 0.02\end{array}$ & $\begin{array}{r}3.79 \\
\pm 0.06\end{array}$ & $\begin{array}{r}0.65 \\
\pm 0.01\end{array}$ & $\begin{array}{r}6.4 \\
\pm 0.2\end{array}$ & $\begin{array}{r}3.14 \\
\pm 0.03\end{array}$ \\
\hline 605 & Al & $\begin{array}{r}2.00 \\
\pm 0.05\end{array}$ & $\begin{array}{r}4.26 \\
\pm 0.15\end{array}$ & $\begin{array}{r}0.87 \\
\pm 0.03\end{array}$ & $\begin{array}{r}97 \\
\pm 0.4\end{array}$ & $\begin{array}{r}3.28 \\
\pm 0.04\end{array}$ \\
\hline 627 & $\mathrm{Cu}$ & $\begin{array}{r}1.69 \\
\pm 0.03\end{array}$ & $\begin{array}{r}4.79 \\
\pm 0.06\end{array}$ & $\begin{array}{r}1.22 \\
\pm 0.03\end{array}$ & $\begin{array}{r}15.3 \\
\pm 0.4\end{array}$ & $\begin{array}{r}3.50 \\
\pm 0.03\end{array}$ \\
\hline 607 & W & $\begin{array}{r}1.80 \\
\pm 0.04\end{array}$ & $\begin{array}{r}5.38 \\
\pm 0.06\end{array}$ & $\begin{array}{r}1.72 \\
\pm 0.05\end{array}$ & $\begin{array}{r}24.2 \\
\pm 0.7\end{array}$ & $\begin{array}{r}3.83 \\
\pm 0.03\end{array}$ \\
\hline 654 & W & $\begin{array}{r}2.04 \\
\pm 0.05\end{array}$ & $\begin{array}{r}5.85 \\
\pm 0.08\end{array}$ & $\begin{array}{r}1.92 \\
\pm 0.06\end{array}$ & $\begin{array}{r}29.4 \\
\pm 0.9\end{array}$ & $\begin{array}{r}3.88 \\
\pm 0.04\end{array}$ \\
\hline 628 & W & $\begin{array}{r}2.22 \\
\pm 0.05\end{array}$ & $\begin{array}{r}6.28 \\
\pm 0.08\end{array}$ & $\begin{array}{r}2.06 \\
\pm 0.06\end{array}$ & $\begin{array}{r}33.9 \\
\pm 1.0\end{array}$ & $\begin{array}{r}3.88 \\
\pm 0.04\end{array}$ \\
\hline
\end{tabular}

$\mathrm{T}_{0}=1673 \mathrm{~K}, \rho_{0}=2.61 \mathrm{Mg} \mathrm{m}^{-3}$, from Stebbins et al. [1984].

a Measured (see equation (3) in text).

${ }^{b}$ Calculated.

$$
\mathrm{P}_{\mathrm{T}}=\frac{\mathrm{P}_{\mathrm{C}}\left(\mathrm{V}_{\mathrm{OC}}-\mathrm{V}\right) / 2-\mathrm{P}_{\mathrm{C}}(\mathrm{V} / \gamma)-\int_{\mathrm{T}_{\mathrm{C}}}^{\mathrm{T}} \mathrm{C}_{\mathrm{P}} \mathrm{dT}}{\left(\mathrm{V}_{\mathrm{OT}}-\mathrm{V}\right) / 2-\mathrm{V} / \gamma}
$$

where $V_{0}$ indicates 1-atm specific volume and the additional subscripts $\mathrm{C}$ and $\mathrm{T}$ refer to states at room temperature and high temperature, respectively. $C_{P}$ is the specific heat at constant pressure [Robie et al., 1978]. It was first assumed that the Gruneisen parameter is dependent only on volume such that $\gamma=\mathrm{V} \gamma_{0} / \mathrm{V}_{0}$, where $\gamma_{0}=1.52$ is the 1-atm Gruneisen parameter [McQueen et al., 1970]. A second calculation was made assuming $\gamma$ constant; i.e. $\gamma=$ 1.52 for all pressures. Values assumed in the calculation of the high-temperature Hugoniot are given together with the experimental results in Table 3 . The experimentally measured point lies close to the calculated curves at high temperatures. Further experiments are planned to constrain better the high-temperature shock equation of state of molybdenum. For reducing our data in this work we used the calculated equation of state with $\gamma / \mathrm{V}=$ const and the parameters listed in Table 3.

\section{Impedance Matching}

We developed an iterative impedance matching procedure for determining the shock velocity and particle velocity of the sample from measurements of the projectile velocity and the total shock transit time through the molten silicate sample plus the Mo cover plate. The propagation of errors was calculated following the method of Jackson and Ahrens [1979].

To start the procedure, we assume that the shock state in the molybdenum cover plate is the same as that in the molybdenum driver plate. The sample shock velocity ( $\left.\mathbf{U}_{\mathrm{SS}}\right)$ in this case is given by

$$
\mathrm{U}_{\mathrm{SS}}=\frac{\mathrm{d}_{\mathrm{S}}}{\mathrm{t}_{\mathrm{T}}-\mathrm{d}_{\mathrm{C}} / \mathrm{U}_{\mathrm{SD}}}
$$

where $d_{S}$ and $d_{C}$ are sample and cap thicknesses, respectively, $t_{T}$ is the total transit time, and $U_{S D}$ is the shock velocity in the driver plate. Here $U_{S D}$ is calculated from

$$
\mathrm{U}_{\mathrm{SD}}=\mathrm{c}+\mathrm{s} \mathrm{U}_{\mathrm{PD}}
$$

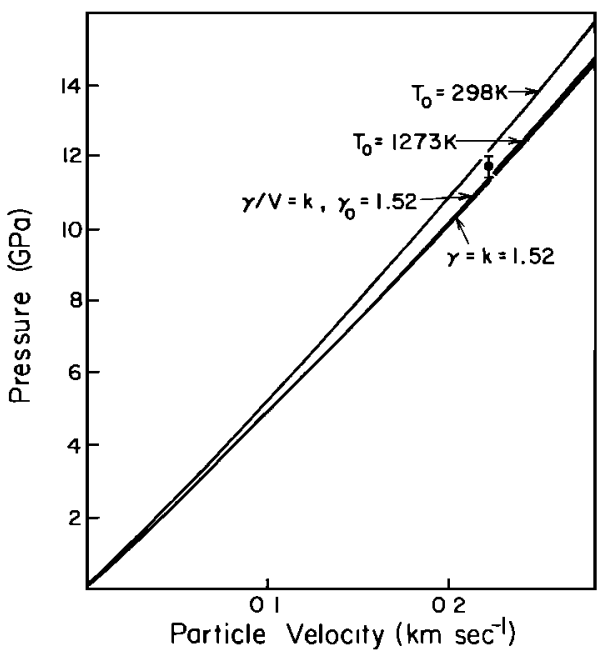

Fig. 6. Result of shock wave equation of state experiment on molybdenum initially at $1273 \mathrm{~K}$. Two calculated Hugoniot curves (see text) centered at $1273 \mathrm{~K}$ are also shown assuming $\gamma=1.52$ and $\gamma / \mathrm{V}=$ const, $\gamma_{0}=1.52$. The experimental point can be fit by the calculated curve barely within experimental error. The effect of the differing assumptions about $\gamma$ is minor. The Hugoniot for molybdenum centered at room temperature is also shown (equation of state parameters are (rom Marsh [1980]). 
TABLE 3. Molybdenum Equation of State Parameters

Parameter Value

\section{Parameters Used to Calculate High-Temperature Hugoniot}

$\begin{array}{ll}\rho_{0} & 10.182 \mathrm{~g} \mathrm{~cm}^{-3}{ }^{2} \\ \alpha & 2.07 \times 10^{-5} \mathrm{~K}^{-1} \mathrm{~b} \\ \gamma_{\mathrm{o}} & 1.522^{\mathrm{c}} \\ \mathrm{c} & 5.14 \mathrm{~km} \mathrm{~s}^{-1}{ }^{\mathrm{d}} \\ \mathrm{s} & 1.22 \mathrm{~d} \\ \mathrm{C}_{\mathrm{P}} & 34.139-4.4926 \times 10^{-3} \mathrm{~T}+3.7012 \times 10^{-6} \mathrm{~T}^{2}-1.5722 \\ & \times 10^{2} \mathrm{~T}^{-0.5} \mathrm{e}\end{array}$

\section{Calculated Hugoniot at $1300 \mathrm{~K}$ I}

$\begin{array}{ll}\rho_{0} & 9.973 \mathrm{gcm}^{-3} \\ \text { c } & 5.06 \mathrm{~km} \mathrm{~s}^{-1} \\ \mathrm{~s} & \mathbf{1 . 2 4}\end{array}$

\section{Measured Hugoniot at $1300 \mathrm{~K}$}

$\begin{array}{ll}\mathrm{U}_{\mathrm{S}} & 5.33 \pm 0.10 \mathrm{~km} \mathrm{~s}^{-1 ~ a} \\ \mathrm{U}_{\mathrm{P}} & 0.219 \pm 0.003 \mathrm{~km} \mathrm{~s}^{-1 ~ a} \\ \mathrm{P}_{\mathrm{H}} & 11.63 \pm 0.25 \mathrm{GPa}^{\mathrm{g}} \\ \rho_{\mathrm{H}} & 10.400 \pm 0.014 \mathrm{~g} \mathrm{~cm}^{-1 ~}\end{array}$

a measured.

b Touloukian et al. [1970].

c McQueen et al. [1970].

$d$ Robie et al. [1978]; coefficients in the equation $\mathrm{U}_{\mathrm{s}}=\mathrm{c}+\mathrm{U}_{\mathrm{PS}}$.

Marsh [1980].

Calculated as described in text.

s Calculated from Rankine-Hugoniot equations.

where $c$ and $s$ are the linear shock wave velocity-particle velocity Hugoniot coefficients describing the equation of state of the hot molybdenum driver plate. In the case of a hypothetical hot Mo impactor the driver particle velocity $\mathrm{U}_{\mathrm{PD}}$ is given by

$$
\mathrm{U}_{\mathrm{PD}}=\mathrm{U}_{\mathrm{imp}} / \mathbf{2}
$$

Thus, in Figure 7 we estimate that the initial shock state in the driver and cap is at point $D$.

Using $U_{S S}$ given by equation (6), an estimate of the shock state in the sample is given by an impedance match solution (Figure 7). Again, when the driver and flyer plates are of the same material, the equation of continuity of stress across the driver plate-sample in terface is given by

$$
\rho_{0 \mathrm{D}}\left(\mathrm{U}_{\mathrm{lmp}}-\mathrm{U}_{\mathrm{PS}}\right)\left[\mathrm{c}+\mathrm{s}\left(\mathrm{U}_{\mathrm{Imp}}-\mathrm{U}_{\mathrm{PS}}\right)\right]=\rho_{0 \mathrm{~S}} \mathrm{U}_{\mathrm{SS}} \mathrm{U}_{\mathrm{PS}}
$$

Here $U_{1 m p}$ is projectile velocity, $\rho_{0 S}$ and $\rho_{0 D}$ are the initial sample and driver densities, and $\mathrm{U}_{\mathrm{PS}}$ is the sample particle velocity. Equation (9) is solved as a quadratic equation for $U_{P S}$. This is shown graphically in Figure 7 for a molybdenum flyer and driver, giving state $S_{1}$. As shown in Table 2, flyer plates other than Mo were used in our experiments; the actual impedance match solutions for the particle velocities $U_{P D}$ and $U_{P S}$ (i.e., analogous to Equations (7) and (8)) took into account the equation of state of the flyer plate [see Ahrens, 1987].

A second assumption is then made to constrain better the shock state in the molybdenum cover plate. The sample equation of state upon shock reflection is approximated by the straight line of slope - $\rho_{0 S} \mathrm{U}_{S S}$ and a state in the molybdenum cover calculated from the equation of continuity of stress across the sample-cover plate interface (state $\mathrm{C}_{1}$, Figure 7):

$$
\rho_{0 \mathrm{D}} \mathrm{U}_{\mathrm{PC}}\left(\mathrm{c}+\mathrm{s} \mathrm{U}_{\mathrm{PC}}\right)=\rho_{0 \mathrm{~S}} \mathrm{U}_{\mathrm{SS}}\left(2 \mathrm{U}_{\mathrm{PS}}-\mathrm{U}_{\mathrm{PC}}\right)
$$

Then $U_{P C}$, the particle velocity in the molybdenum cover plate, is obtained from solution of Equation (10). Using the known molybdenum equation of state, it is now possible to recalculate the sample shock velocity,

$$
\mathrm{U}_{\mathrm{SS}}=\frac{\mathrm{d}_{\mathrm{S}}}{\mathrm{t}_{\mathrm{T}}-\mathrm{d}_{\mathrm{C}} /\left(\mathrm{c}+\mathrm{sU}_{\mathrm{PC}}\right)}
$$

and hence make a second estimate of the sample shock state $\left(\mathrm{S}_{2}\right.$, Figure 7$)$.

After three iterations using this procedure, values of $U_{S S}$ and $U_{P S}$ have converged to within the experimental uncertainties.

In the procedure described above, the particle velocity of the reflected shock wave in the silicate was assumed to be linear with pressure. We have also considered the possibility of a nonlinear relationship. After fitting our data in the shock velocity-particle velocity plane with an equation of the same form as Equation (7), we used the quadratic equation

$$
\mathrm{P}=\left[\mathrm{C}-\mathrm{S}\left(\mathrm{U}_{\mathrm{p}}-2 \mathrm{U}_{\mathrm{PS}}\right)\right]\left(2 \mathrm{U}_{\mathrm{PS}}-\mathrm{U}_{\mathrm{p}}\right) \rho_{0 \mathrm{~S}}
$$

based on the entire data set for $U_{\mathrm{p}} \leq 1.8 \mathrm{~km} \mathrm{~s}^{-1}$ as a refined approximation to the curve $\mathrm{S}_{2}-\overline{\mathrm{C}}_{2}$ instead of a line of slope $-\rho_{O S} \mathrm{U}_{\mathrm{SS}}$. As an example, using the results for shot 607 at $24.2 \mathrm{GPa}$ and using the quadratic form above instead of $-\rho_{0 S} U_{S S}$ for the reflected Hugoniot of liquid yields a slightly higher shock velocity of $6.0 \mathrm{~km} \mathrm{~s}^{-1}$ in the Mo cap instead of $5.9 \mathrm{~km} \mathrm{~s}^{-1}$. This in turn reduces the shock velocity in the sample from 5.38 to $5.35 \mathrm{~km} \mathrm{~s}^{-1}$. The effect then is to reduce the Hugoniot pressure from 242 to $24.0 \mathrm{GPa}$ and to increase the density from 3.83 to $3.84 \mathrm{Mg}$ $\mathrm{m}^{-3}$. All these changes are within the experimental uncer-

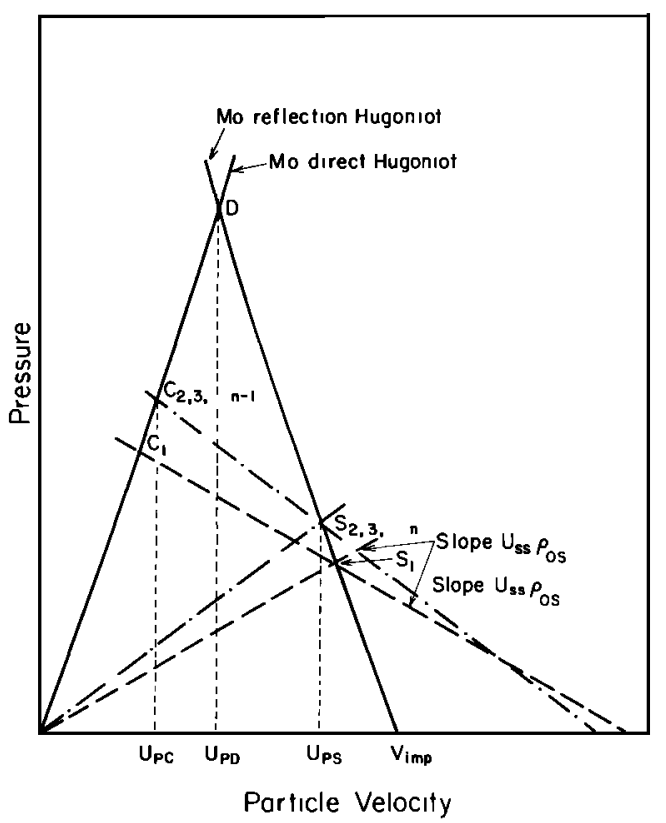

Fig 7. Method for data reduction of molten silicate equation of state experiments. The solid curves represent the direct and reflected Hugoniots of molybdenum at high temperature. Molybdenum flyer plate is assumed. The initial estimate of shock velocity in the molten silicate (equation (6)) allows an impedance match solution of the sample shock state (equation (9)) (dashed line intersection with Mo reflection Hugoniot, state $S_{1}$ ) Assuming the release state in the sample lies along this straight-lıne "sample reflection Hugoniot," an estimate of the shock state in the Mo cap is made by impedance match (equation (10)). Subsequent estimates of sample shock velocity yielding states $S_{2,3}$, n and shock states in the Mo cap $\left(\mathrm{C}_{2,3} \mathrm{n}_{-1}\right)$ are indicated by the dash-dot lines and do not change with in the experimental uncertainties 
tainties, demonstrating that our results are not sensitive to different approximations to the form of the molten silicate reflected Hugoniot.

\section{Results}

The results of shock wave experiments on molten $\mathrm{An}_{0.36} \mathrm{Di}_{0.64}$ are given in Table 2 and shown in the particle velocity-shock velocity plane in Figure 8 and in pressuredensity space in Figure 9. From atmospheric pressure up to $25 \mathrm{GPa}$, there is a substantial ( $\sim 50 \%)$, gradual increase in density along the Hugoniot. Above $25 \mathrm{GPa}$ the trend of gradual compression ceases, and the material becomes considerably stiffer, leading to little increase in density with increasing pressure. The $\mathrm{U}_{\mathrm{S}}-\mathrm{U}_{\mathrm{P}}$ data in both the low- and high-pressure regions can be fit well by straight lines given by

$$
\mathrm{U}_{\mathrm{S}}=3.06+1.36 \mathrm{U}_{\mathrm{p}} \mathrm{km} \mathrm{s}^{-1}
$$

$\left(\mathrm{r}^{2}=0.99\right)$ for the low-pressure regime and

$$
\mathrm{U}_{\mathrm{S}}=0.85+2.63 \mathrm{U}_{\mathrm{P}} \mathrm{km} \mathrm{s}^{-1}
$$

$\left(r^{2}=1.00\right)$ for the high-pressure regime. There is no fundamental significance to our choice of a linear fit to these data or in general to the number of parameters required to fit $U_{S}-U_{P}$ data [Ruoff, 1967]. However, a sudden structural rearrangement over a narrow pressure interval would lead to a change in the slope of the $U_{S}-U_{P}$ curve. From the goodness of fit to the $\mathrm{U}_{\mathrm{S}}-\mathrm{U}_{\mathrm{P}}$ data in the low-pressure segment of the data set, we estimate that a structural rearrangement under shock conditions could not be detected from these data unless it resulted in a density jump of $\gtrsim$ $0.15 \mathrm{Mg} \mathrm{m}^{-3}$ at the low-pressure end of the data. At the highest-pressure end a density jump of $\gtrsim 0.05 \mathrm{Mg} \mathrm{m}$ could be detected.

\section{Fitting the Data to a Birch-Murnaghan Equation of State}

At a particular density, a Hugoniot or shock state lies at a higher pressure than an isothermal or isentropic state because of the irreversible energy generated during the shock process. It is useful in discussing processes occurring in planetary interiors to refer to isothermal or isentropic states. For metals, oxides, and silicates a Mie-Gruneisen equation of state has been used successfully in reducing Hugoniot data to isothermal or isentropic states [McQueen et al., 1970; Ahrens et al., 1969], and we have used it here.

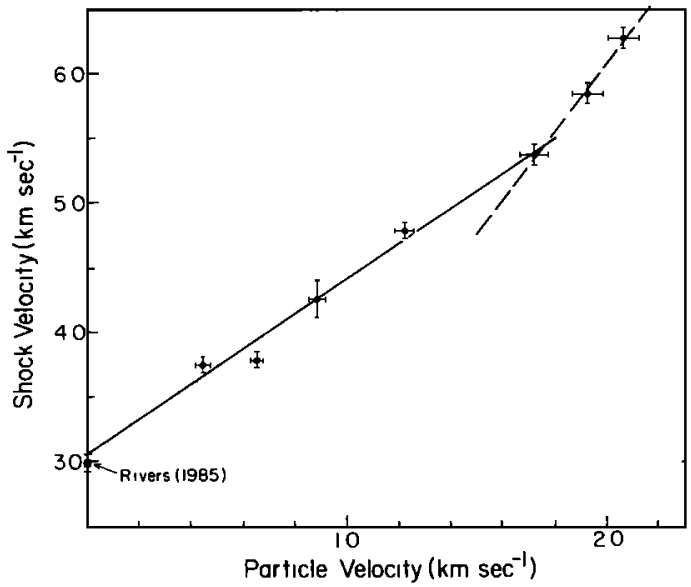

Fig. 8. Shock velocity-particle velocity plane with linear fits to the low- and high-pressure data. Below $\sim 25 \mathrm{GPa}$ : $\mathrm{U}_{\mathrm{S}}=3.06+1.36 \mathrm{U}_{\mathrm{P}} \mathrm{km} \mathrm{s}^{-1}, \mathrm{r}^{2}=0.99$. At pressures higher than $\sim 25 \mathrm{GPa}: \mathrm{U}_{\mathrm{S}}=0.85+2.63 \mathrm{U}_{\mathrm{P}} \mathrm{km} \mathrm{s}^{-1}, \mathrm{r}^{2}=$ 1.00. The point plotted on the shock velocity axis is based on sound speed measurements on anorthite-diopside liquid mixtures from Rivers [1985].

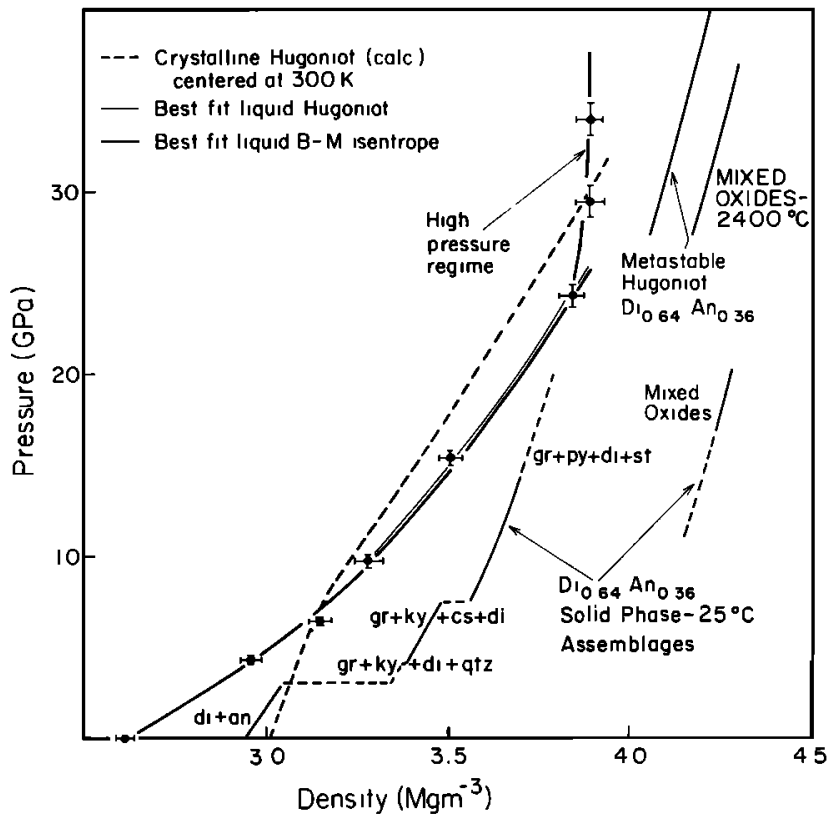

Fig. 9. Results of equation of state experiments on molten silicate shown in the pressure density plane. The 1-atm point is calculated from Stebbins et al. [1984]. Best fit Hugoniot and Birch-Murnaghan isentrope are shown for the data up to $25 \mathrm{GPa}$. The isentrope is centered at 1673 $\mathrm{K}$ with $\mathrm{K}_{0 \mathrm{~S}}=24.2 \mathrm{GPa}$ and $\mathrm{K}^{\prime}=4.85$. The dashed curve is a calculated solid ( $\mathrm{T}_{0}=300 \mathrm{~K}$ ) Hugoniot based on the experimentally determined Hugoniots for diopside and anorthite. The metastable Hugoniot is calculated from Boslough et al. [1986] and Svendsen and Ahrens [1983].

The difference in energy at constant volume between a Hugoniot state and the state on an isentrope is given in the Mie-Gruneisen formulation by

$$
\mathrm{E}_{\mathrm{H}}-\mathrm{E}_{\mathrm{S}}=\frac{\mathrm{V}}{\gamma}\left(\mathrm{P}_{\mathrm{H}}-\mathrm{P}_{\mathrm{S}}\right)
$$

where the $\mathrm{H}$ subscript refers to states along the Hugoniot and the $S$ subscript refers to energy and pressure along the third-order isentrope centered at the initial pressure and temperature. For the isentrope we assume the BirchMurnaghan form

$$
\mathrm{P}_{\mathrm{S}}=\frac{3}{2} \mathrm{~K}_{\mathrm{oS}}\left(\mathrm{X}^{7}-\mathrm{X}^{5}\right)\left[1-\xi\left(\mathrm{X}^{2}-1\right)\right]
$$

where

$$
\mathrm{X} \equiv\left(\mathrm{V}_{0} / \mathrm{V}\right)^{1 / 3}
$$

and

$$
\xi \equiv 3\left(4-K^{\prime}\right) / 4
$$

Here $K_{0 S}$ is the bulk modulus $\left(K_{S}\right)$, at the initial temperature and pressure and

$$
\mathrm{K}^{\prime} \equiv\left(\partial \mathrm{K}_{\mathrm{S}} / \partial \mathrm{P}\right)_{\mathrm{S}}
$$

evaluated at $V=V_{0}$. The initial (i.e., preshock) state signified by the zero subscript has been approximated as zero pressure. The energy increase along an isentrope for a third-order Birch-Murnaghan equation of state is

$$
\begin{gathered}
\mathrm{E}_{\mathrm{S}}=\frac{9}{2} \mathrm{~K}_{0 \mathrm{~S}} \mathrm{~V}_{0}\left\{(\xi+1)\left(\frac{\mathrm{X}^{4}}{4}-\frac{\mathrm{X}^{2}}{2}+\frac{1}{4}\right)\right. \\
\left.-\xi\left[\frac{\mathrm{X}^{6}}{6}-\frac{\mathrm{X}^{4}}{4}+\frac{1}{12}\right)\right\}
\end{gathered}
$$

Energy increase along the Hugoniot is given by the Rankine-Hugoniot equation for conservation of energy, namely, 


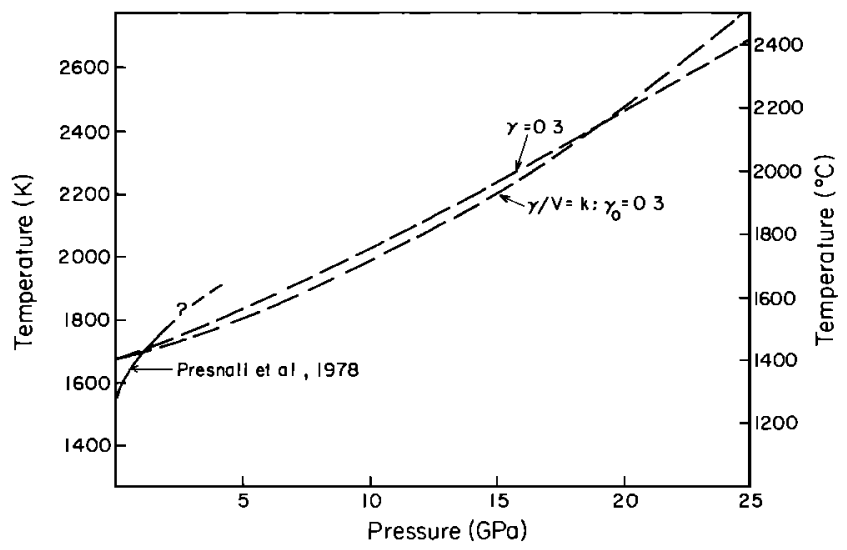

Fig. 10. Calculated shock temperatures for $\mathrm{An}_{0.36} \mathrm{Di}_{\mathbf{0 . 6 4}}$ with $\mathrm{T}_{0}=1673 \mathrm{~K}$. The liquidus temperature for this composition is also shown up to $2 \mathrm{GPa}$ [after Presnall et al., 1978]. The two shock temperature curves are calculated assuming $\gamma=0.3$ const and $\gamma / V=$ const, $\gamma_{0}=\mathbf{0 . 3}$.

$$
\mathrm{E}_{\mathrm{H}}=\left(\mathrm{P}_{\mathrm{H}}+\mathrm{P}_{0}\right)\left(\mathrm{V}_{0}-\mathrm{V}\right) / 2 .
$$

Using the experimental data along the low-pressure part of the Hugoniot $\left(U_{p} \lesssim 18 \mathrm{~km} \mathrm{~s}^{-1}\right.$; Figure 8) plus the 1-atm density and assuming a Mie-Gruneisen equation of state we have fit the Birch-Murnaghan parameters $K_{0 S}$ and $K^{\prime}$ by the method of least squares. The function that was minimized is

$$
\sum_{1}\left(P_{i \text { calc }}-P_{1 \text { obs }}\right)^{2}=\sum_{i}\left[\frac{E_{s i}-P_{s i} V_{1} / \gamma}{\frac{V_{0}-V_{i}}{2}-\frac{V_{i}}{\gamma}}-P_{i ~ o b s}\right]^{2}
$$

The subscript $\mathrm{i}$ refers to an individual experiment, $\mathrm{P}_{\mathrm{i} \text { obs }}$ and $V_{i}$ are the observed Hugoniot pressure and volume for each experiment, and $P_{s i}$ and $E_{s i}$ were calculated using Equations (13) and (14), respectively, at volume $\mathrm{V}=\mathrm{V}_{\mathrm{i}}$. The 1-atm Gruneisen parameter $\gamma_{0}$ was calculated from values of $\alpha, K_{s}$, and $C_{p}$ derived from Bottinga and Weill [1970], Rivers [1985], and Well et al. [1980]. We have also assumed, as described earlier, that $\gamma=V \gamma_{0} / V_{0}$. For $\gamma_{0}=0.3$, the best fit Birch-Murnaghan parameters for the low-pressure regime are $\mathrm{K}_{0 \mathrm{~S}}=24.2 \mathrm{GPa}$ and $\mathrm{K}^{\prime}=4.85$. As an alternative, we could have used the zero-pressure sound speed implied by the linear fit to the $U_{S}-U_{P}$ data (i.e., $c=306 \mathrm{~km} \mathrm{~s}^{-1}$ from equation (12)) along with the 1atm density $\left(\rho_{\mathrm{o}}=261 \mathrm{Mg} \mathrm{m}^{-3}\right)$ to calculate a value of $\mathrm{K}_{0 S}$ This approach yields a (similar) value of $\mathrm{K}_{\mathrm{OS}}=\mathbf{2 4 . 4}$ $\mathrm{GPa}$. Thus we get a similar bulk modulus using either the linear shock velocity-particle velocity relation (Equation (12)) or Birch-Murnaghan equation of state (Equation (15)). These values differ slightly from those of Rigden et al. [1984], a larger data set and a modified fitting procedure were used. Using Rivers' [1985] ultrasonic velocity data for molten silicates at $1 \mathrm{~atm}$, we calculate a value of $\mathrm{K}_{0 \mathrm{~S}}=$ $23.3 \mathrm{GPa}$ for the composition $\mathrm{An}_{0}{ }_{36} \mathrm{Di}_{0.64}$, in good agreement with our results

\section{Shock Temperatures}

Temperatures as a function of volume along both the Hugoniot and the isentrope centered at the preshock pressure and temperature can also be estimated with the MieGruneisen equation of state In this case,

$$
\mathrm{T}_{\mathrm{H}}-\mathrm{T}_{\mathrm{S}}=\frac{\mathrm{V}}{\gamma \mathrm{C}_{\mathrm{V}}}\left(\mathrm{P}_{\mathrm{H}^{-}}-\mathrm{P}_{\mathrm{S}}\right)
$$

where $T_{H}$ and $T_{S}$ are temperatures along the Hugoniot and isentrope, respectively, and $\mathrm{C}_{\mathrm{V}}$ is the specific heat at constant volume. The temperature along the isentrope is given by

$$
\mathrm{T}_{\mathrm{S}}=\mathrm{T}_{0} \exp \left[-\int_{\mathrm{V}_{0}}^{\mathrm{V}} \frac{\gamma(\mathrm{V})}{\mathrm{V}} \mathrm{dV}\right)
$$

where $T_{0}$ is the initial temperature. For the assumed volume dependence of $\gamma$, this reduces to

$$
\mathrm{T}_{\mathrm{S}}=\mathrm{T}_{0} \exp \left\{-\gamma_{0}\left(\frac{\mathrm{V}}{\mathrm{V}_{0}}-1\right)\right\}
$$

Shock temperatures have been calculated (assuming $\mathrm{C}_{\mathrm{V}}$ is given by $3 \mathrm{R}$ per mole atom) by substituting Equation (20) in to Equation (18). Calculated shock temperatures for $\mathrm{An}_{036} \mathrm{Di}_{0.64}$ initially at $1673 \mathrm{~K}$ are shown in Figure 10 . At $\sim 25 \mathrm{GPa}$, the temperature rise is expected to be $\sim 900 \mathrm{~K}$. Also shown is the liquidus temperature for this composition determined experimentally at low pressures by Presnall et al. $[1978]$.

\section{Discussion}

In our experiments, we drive a shock wave through a silicate liquid and determine the pressure and density of the shocked state. It is difficult, however, to establish with absolute confidence what phases are present in the shocked state. The principal problem, as shown in Figure 10, is that although our sample is initially totally molten, with increasing pressure the states achieved during the shock could eventually lie within the stability fields of liquid plus solid or solid phase(s) alone. Could the sample crystallize, partially or completely, during the brief time that it is shocked, if the Hugoniot temperature lies below the liquidus or solidus? Are we studyıng metastable liquid states? Even if the liquid does not crystallize, are the time scales of the present shock wave experiments sufficient to reach an equilibrium or "relaxed" metastable state for the liquid; i.e., are we studying a glass or a liquid?

We do not know for certain the answers to these questions. However, every line of reasoning that we have followed strongly suggests that at least up to $25 \mathrm{GPa}$, our shock experiments on the model basaltic composition are yielding insights in to the relaxed equation of state of metastable liquid. The very stiff material encountered above 25 $\mathrm{GPa}$ in our experiments is of special interest, and possible explanations for it are discussed below.

The most convincing evidence that we are studying relaxed liquid states is the fact that the 1 -atm bulk modulus that we obtain from fitting our data to a BirchMurnaghan isentrope is essentially identical to the value based on measurements of ultrasonic velocities by Rivers [1985]. According to Rivers [1985], the unrelaxed bulk modulus should be about a factor of 5 higher than the relaxed value. We acknowledge that the use of a BirchMurnaghan equation is arbitrary, but as discussed above, similar results are obtained if the raw Hugoniot data are fit to a linear shock velocity-particle velocity relation [Rigden et al., 1984]. We believe that the observed similarity in the values of $\mathrm{K}_{0 \mathrm{~S}}$ obtained independently by us and by Rivers [1985] would be a remarkable coincidence if our pressuredensity points referred to anything but essentially relaxed liquid states.

At first glance, it may seem a little surprising that silicate melts could relax on the time scale of a shock experiment. As discussed below, the high densities achieved in our experiments probably indicate that structural changes occur in the melt (e.g., increasing coordination of $\mathrm{Al}$ and $\mathrm{Si}$ by oxygen) with increasing pressure, so our conclusion that we are probing relaxed states would imply that structural changes of this sort can occur on the time scale required to reach the shocked state. In a shock wave experiment, one characteristic time is the rise time of the shock. This can be estimated to be [Jeanloz and Ahrens, 1979]

$$
\tau_{\mathrm{r}}=\frac{\eta \mathrm{U}_{\mathrm{P}}}{\mathrm{U}_{\mathrm{S}} \Delta \mathrm{P}_{\mathrm{V}(\max )}}
$$

where $\Delta P_{V(\max )}$ is the maximum pressure offset between the equilibrium Hugoniot and the Rayleigh line and $\eta$ is effective viscosity. The values of $\Delta \mathrm{P}_{\mathrm{V}}$ for a given $\mathrm{P}_{\mathrm{H}}$ can 
be calculated from the fit to the experimental shock data. The precise value of $\eta$ at a pressure which is of the order of one-half the pressure of the shock state is unknown. Assuming that $\eta=30 \mathrm{P}$, the value at $1 \mathrm{~atm}$ and $1673 \mathrm{~K}$ calculated from Bottinga and Well [1972], shock rise times are expected to be of the order of $10^{-9} \mathrm{~s}$ in our experiments (see Figure 11).

These estimates of the rise time of the shock are comparable to or more than an order of magnitude greater than estimates of the time scale for relaxation of melts in the system anorthite-diopside at $1 \mathrm{~atm}$ and temperatures similar to the initial temperature of our sample [Rivers, 1985]. This value is also consistent with estimates of relaxation times in other basic melts with similar viscosities [Rai et al., 1981; Rivers, 1985]. Ideally, we should compare the rise time of the shock with relaxation time scales under the conditions achieved during the shock, but little information is available to extrapolate to these extremes from known 1-atm values. One approach would be to suppose that curves of constant relaxation time are parallel in PT space to the macroscopic glass transition temperature. Based on measurements up to $7 \mathrm{kbar}$, Rosenhauer et al. [1985] found a slope of $0 \mathrm{~K} \mathrm{kbar}^{-1}$ for the glass transition in anorthite melt and $4 \mathrm{~K} \mathrm{kbar}^{-1}$ for the transition in diopside liquid. The calculated temperature rise along the Hugoniot in our experiments (Figure 10) is greater than or equal to these slopes of the glass transition temperature. Based on this, we would predict, given that relaxation times for melts similar in composition to the one we have studied are of the order of a $10^{-9} \mathrm{~s}$ or lower at $1673 \mathrm{~K}$ and 1 atm, that relaxation times would be similar or lower under the PT conditions achleved in our shock experiments. In retrospect, we conclude that we should not have been surprised to learn that our experiments appear to be capable of probing relaxed states and that our results are so similar to those obtained ultrasonically on much longer time scales $\left(10^{-5} \mathrm{~s}\right.$ [Rai et al., 1981; Rivers, 1985]).

Under what conditions might crystallization take place in a shock wave experiment? A formal way to answer this question is through the use of time-temperaturetransformation curves [e.g., Uhlmann and Klein, 1976; Uhlmann et al., 1981; Cranmer et al., 1981]. Examples of such curves are shown in Figure 11 for lunar glasses and anorthite glass. Basically, these curves map out the conditions of temperature and time scale under which a liquid will or will not crystallize. All curves have a characteristic shape, with a minimum time (the nose, or $\tau_{\text {nose }}$ ) at a temperature that is $\sim 0.77 \mathrm{~T}_{\mathrm{E}}$ (where $\mathrm{T}_{\mathrm{E}}$ is the liquidus temperature). At time scales shorter than $\tau_{\text {nose, }}$ the material cannot crystallize at any temperature. Using the simplified model developed by Uhlmann et al. $[1979,1981]$, we have calculated the location of the nose of the TTT curve for molten $\mathrm{An}_{0.36} \mathrm{Di}_{0.64}$ at $1 \mathrm{~atm}$. Its location $(\tau \sim 100 \mathrm{~s})$ falls within the range of lunar glass curves taken from the literature. Note that the rise time of the shock is about 11 orders of magnitude shorter than $\tau_{\text {nose }}$ at $1 \mathrm{~atm}$.

If $\tau_{\text {nose }}$ does not move much with increasing pressure, then our intuition that crystallization would be extremely unlikely in a shock wave experiment would be confirmed. Using the model of Uhlmann et al. $[1979,1981]$, we have tried to estimate the position of $\tau_{\text {nose }}$ under the conditions achieved in our experiments. The value of $\tau_{\text {nose }}$ depends on the nucleation and growth rates of crystals and on the viscosity at $\mathrm{T}_{\mathrm{E}}$. In the absence of any information on the pressure dependence of nucleation and growth rates, we have assumed that the 1-atm values hold at all pressures. As an upper limit to $\mathrm{T}_{\mathrm{E}}$, we have assumed a value of 2873 $\mathrm{K}$ at $20 \mathrm{GPa}$, the expected value for forsterite based on the experimental results of Ohtani and Kumazawa [1981]. The viscosities of both anorthite and diopside melt decrease with increasing temperature (summarized by Richet et al. [1986]). The viscosity of molten diopside increases with increasing pressure [Scarfe et al., 1979; Brearley et al., 1986 , but the viscosities of anorthite and other highly polymerized melts are approximately independent of pressure or even decrease with pressure up to a lew tens of kilobars [Kushiro, 1980, 1981] Based on molecular dynamics simulations [Ángell et al., 1982, 1983, 1986], this trend

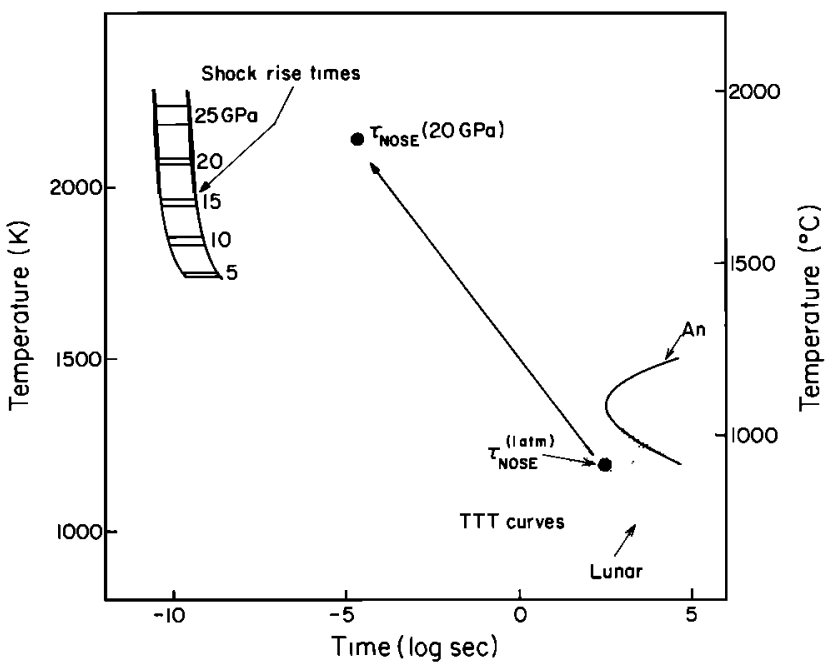

Fig. 11. Comparison of estimated shock rise times with critical cooling time for glass formation from the theory of transformation kinetics. Stippled field encompasses timetemperature-transformation (TTT) curves for formation of lunar glasses taken from the literature [Uhlmann and Klein, 1976; Uhlmann et al., 1981]. Also shown is a TTT curve for anorthite glass [Cranmer et al., 1981]. The value of $\tau_{\text {NOSE }}(1 \mathrm{~atm})$ for $\mathrm{An}_{0.36} \mathrm{Di}_{0.64}$ was calculated using the simplified model of Uhlmann et al., [1979|. The value of $\tau_{\text {NOSE }}(20 \mathrm{GPa})$ represents a likely minimum estimate as described in the text. Shock rise times are calculated as described in the text for $3 \mathrm{P}<\eta<30 \mathrm{P}$. Shock temperatures at different pressures are derived from Figure 10. Shock rise times are more than 5 orders of magnitude less than the critical cooling time for glass formation at 20 $\mathrm{GPa}$, indicating that crystallization is not expected to occur under shock conditions.

may continue up to $50 \mathrm{GPa}$ for some compositions. As an extreme value, taking in to account the increases in $P$ and $\mathrm{T}$, viscosity could decrease by as much as 7 orders of magnitude from $0.77 \mathrm{~T}_{\mathrm{E}}$ at $1 \mathrm{~atm}$ to $0.77 \mathrm{~T}_{\mathrm{E}}$ at $20 \mathrm{GPa}$. These parameters would then lead to an estimate of $\tau_{\text {nose }}$ of the order of $20 \mu$ s under shock conditions (Figure 11). This is still 4-5 orders of magnitude greater than the expected rise time of the shock and again strongly suggests that there is not sufficient time for crystallization to occur under shock conditions.

One way that we can imagine the opportunity for crystallization to be maximized in shock wave experiments is if melt and crystal become very close to each other in structure and composition; under these conditions, the nucleation and growth rates might be strongly enhanced. As we discuss below, the approach of the shock wave densities that we measure at the highest pressures to the densities of mixtures of dense oxides could indicate that the difference in packing between melt and solid at pressures above $25 \mathrm{GPa}$ is small. If so, crystallization may be more likely in the highest-pressure experiments.

There is one final observation that supports the conclusion that at less than $30 \mathrm{GPa}$, crystallization probably did not occur in our experiments. In Figure 9, we plot the calculated solid Hugoniot states of a mixture of initially cold anorthite (which enters a mixed phase above $7 \mathrm{GPa}$ ) and diopside (which remains in this low-pressure phase to 60 $\mathrm{GPa}$ ). The mixture has a lower density than the Hugoniot states of our initially molten sample over most of the pressure range we have studied. If these theoretical solid Hugoniot states, which were obtained by summing the specific volumes along the experimentally determined Hugoniots of crystalline anorthite and diopside, are reasonable approximations to the densities of a crystalline mixture of this composition, the fact that the Hugoniot of the initially molten sample exceeds that of the equivalent solid, 
TABLE 4. Oxide Equations of State

\begin{tabular}{lccccl}
\hline \multicolumn{1}{c}{ Oxide } & $\begin{array}{c}\rho_{\mathrm{o}}{ }^{-3} \\
\mathrm{Mg} \mathrm{m}^{-3}\end{array}$ & $\begin{array}{c}\mathrm{K}_{\mathrm{os}} \\
\mathrm{GPa}\end{array}$ & $\mathrm{K}_{\mathrm{os}}{ }^{\prime}$ & $\gamma_{\mathrm{o}}$ & \multicolumn{1}{c}{ References } \\
\hline Stishovite & 4.2901 & 316 & 4.0 & 1.25 & Weidner et al. [1982] and Davies [1972] \\
Corundum & 3.988 & 253 & 4.3 & 1.32 & Anderson et al. [1968] \\
Lime & 3.345 & 112 & 4.8 & 1.51 & Jeanloz and Ahrens [1980a] \\
Periclase & 3.584 & 163 & 4.27 & 1.32 & Vassiliou and Ahrens [1981] \\
\hline
\end{tabular}

strongly suggests that the high densities that we observe in our experiments are the result of structural changes in the liquid and not the result of crystallization. The discrepancy between our measurements and the equivalent solid Hugoniot is actually even more extreme than appears in Figure 9, since the calculated solid Hugoniot is centered at $300 \mathrm{~K}$ rather than at $1673 \mathrm{~K}$, the initial temperature of our experiments; the high-temperature Hugoniot would be at lower densities than the one shown in Figure 9. Although this line of reasoning supports our conclusion that crystallization probably did not occur in most of our experiments and Ahrens et al. [1977] reported considerable success in modeling the Hugoniots of rocks as mixtures of the Hugoniots of their known constituent mineralogies, we note that this calculation has not taken into account the effects of reaction between the anorthite and diopside components in achieving the high-pressure solid assemblage.

What is the explanation of the abrupt stiffening of the $\mathrm{An}_{036} \mathrm{Di}_{0.64}$ composition that we observe at pressures above $25 \mathrm{GPa}$ ? Perhaps crystallization occurred in these highpressure experiments; as pointed out earlier, we expect that crystallization, if it can ever occur on the time scale of a shock experiment, is more likely in the highest-pressure experiments. A second possibility is that with increasing $\mathrm{P}$ along the PT trajectory of the Hugoniot, relaxation times for the melt phase increase progressively, and in the highest-pressure shock experiments, the rise time of the shock becomes shorter than the relaxation time of the melt. In other words, perhaps the states achieved in the highestpressure experiments are unrelaxed and we are effectively studying glasses rather than melts. Another possibility is that the high compressibility of the melt up to $25 \mathrm{GPa}$ reflects continuous conversion of $\mathrm{Al}$ and $\mathrm{Si}$ from domin antly tetrahedral coordination by oxygen into dominantly octahedral coordination or another kind of structural transformation. Once the structural transformation is complete (e.g., essentially all of the $\mathrm{Al}$ and $\mathrm{Si}$ are octahedrally coordinated), the melts would be expected to stiffen considerably, and perhaps this is what we have detected in the experiments above $25 \mathrm{GPa}$. The similar slopes of the molten silicate Hugoniot above $25 \mathrm{GPa}$ and the metastable Hugoniot of the high-pressure phase and the expected behavior of the equilibrium solid assemblages at low temperature indicated on Figure 9 are consistent with the hypothesis that conversion of the liquid structure to one approaching that of the isocompositional solid assemblage is essentially complete above $25 \mathrm{GPa}$. We are not sure which, if any, of these explanations is correct. We note, however, that this behavior has not been observed in shock wave experiments on pure anorthite or diopside melt over a similar pressure range (S. M. Rigden et al., manuscript in preparation, 1987).

\section{Microscopic Significance of the Compression of Model Basaltic Liquid}

The apparent smooth compression of $\mathrm{An}_{0.36} \mathrm{Di}_{0.64}$ to 25 $\mathrm{GPa}$ contrasts with the expected behavior of the crystalline equivalent. Under both dynamic and static high pressure, mixtures of crystalline anorthite and diopside would be expected to show discontinuous increases in density as a succession of phase transformations occur (Figure 9). Although the precise locations of the mixed phase regions under dynamic and static compressions are not well known, there can be little doubt that abrupt changes in slope both in $P-\rho$ and $U_{s}-U_{p}$ space will be observed in compression of crystalline anorthite-diopside mixtures over the pressure range we have studied [Liu, 1979, Goldsmith, 1980; Jeanloz and Ahrens, 1980b; Boslough et al., 1986].

The absence of obvious discontinuous jumps in density for the molten silicate sample suggests that compression occurs by continuous changes in melt structure. Given the distribution of our data points in P- $\rho$ space, we cannot rule out essentially discontinuous increases in density or narrow intervals of pressure over which density increases anomalously. However, given the fact that in $\mathrm{U}_{\mathrm{s}}-\mathrm{U}_{\mathrm{p}}$ space the data in the low-pressure regime can be fit closely by a straight line (Figure 8), we think that such discontinuities are unlikely. If they occur, the magnitude of such anomalous density increases would have to be less than $0.15 \mathrm{Mg} \mathrm{m}{ }^{-3}$ at the low-pressure end of our data, and less than $0.05 \mathrm{Mg} \mathrm{m}^{-3}$ at the high-pressure end, based on the spacing of our data points.

Our measurements of density are not sufficient to specify the structural changes that occur in silicate melts in response to increasing pressure, but they can be used to test or constrain models of these microscopic changes One possibility, based on analogy with phase changes observed in crystalline silicates [e.g. Waff, 1975], on studies of solidliquid phase equilibria [Boettcher et al., 1982, 1984], on spectroscopic studies of glasses quenched from high pressures [Ohtani et al., 1985], and on the results of molecular dynamics simulations of melt structure [e.g., Woodcock et al., 1976; Matsui and Kawamura, 1980, 1984; Matsui et al., 1982; Angell et al., 1982, 1983, 1987] is that major increases in melt density with pressure reflect transformation of $\mathrm{Al}$ and $\mathrm{Si}$ (and perhaps $\mathrm{Mg}$ ) from predominantly four-fold coordination by oxygen ions at low pressures to predominantly six-fold coordination at elevated pressures.

If such a transformation occurs, we think it likely that at sufficiently high pressures, when essentially all of the $\mathrm{Si}$ and $\mathrm{Al}$ are octahedrally coordinated, the partial molar volumes of $\mathrm{SiO}_{2}$ and $\mathrm{Al}_{2} \mathrm{O}_{3}$ in melts can be approximated to within several percent by the molar volumes of simple oxides such as stishovite and corundum (S. M. Rigden et al., manuscript in preparation, 1987). We also anticipate that once the conversion to six-fold coordination for $\mathrm{Si}$ and Al is essentially complete, the melts would stiffen considerably and their elastic properties might approach those of crystalline materials under the same conditions. Our results are consistent with these expectations: at $\sim 25 \mathrm{GPa}$ (and a temperature of $\sim 2400^{\circ} \mathrm{C}$; Figure 10), the density of the model basaltic melt is $\sim 3.84 \mathrm{Mg} \mathrm{m}^{-3}$; under similar conditions, a mixture of crystalline dense oxides (stishovite, corundum, lime, periclase) of the same composition would have a density of $\sim 4.1 \mathrm{Mg} \mathrm{m}^{-3}$ (using equation of state data for oxides summarized in Table 4 and the assumptions $\gamma_{0} \rho_{0}$ is constant and $\mathrm{C}_{\mathrm{V}}=3 \mathrm{R}$ ). Thus the density achieved in our experiments just as the melt stiffens at 24 $\mathrm{GPa}$ is only about $6 \%$ lower than that of an octahedrally 
coordinated crystalline equivalent. Similar results, including the abrupt stiffening once the octahedrally coordinated density is closely approached, have been observed on shock compression of silica and anorthite glass [Wackerle, 1962 Boslough et al., 1986]. The results of Lyzenga et al. [1982 for stishovite and Jeanloz and Heinz $[1984]$ on a silicate perovskite composition also indicate that at pressures of several hundred kilobars, the volumes of liquids exceed those of coexisting solids (in which $\mathrm{Si}$ is mostly octahedrally coordinated) by at most a few percent. We conclude that available data are consistent with the hypothesis that at pressures of a few hundred kilobars, $\mathrm{Si}$ and $\mathrm{Al}$ are essentially entirely octahedrally coordinated by oxygen ions and that most of the compression of aluminosilicate melts observed up to these pressures can be accounted for by the substantial decreases in volume that usually accompany changes from tetrahedral to octahedral coordination of Si and Al.

We emphasize that the correspondence between the melt densities observed by us at high pressures and the densities of equivalent solids with octahedrally coordinated $\mathrm{Si}$ and $\mathrm{Al}$ is not sufficient to conclude that these coordinations are present in the melt under these conditions. There are many potentially important modes of compression other than increasing coordination of cations by oxygen ions in highly polymerized aluminosilicate melts that might account for this correspondence, including distortion of the linkages between tetrahedra, decreasing sizes of rings of tetrahedra [e.g., Grimsditch, 1984; Fiori and Devine, 1986], and progressive depolymerization of the tetrahedral network by creation of defects and nonbridging oxygens. However, since it is difficult to predict in a quantitative way how melt density would change with pressure if such mechanisms operated, we cannot check their consistency with our data set. To account for the densities observed at high pressures in the model basaltic melt, the partial molar volume of silica in melts above $24 \mathrm{GPa}$ must be about $50 \%$ of the 1 -atm value. Since coesite, whose structure is based on four-membered rings of silica tetrahedra, has a volume under these conditions that is about $80 \%$ of the partial molar volume of silica in melts at 1 atm [Bottinga et al., 1982], we conclude that if ring size change is the principal mode of compression up to pressures of $24 \mathrm{GPa}$, the structures achieved during shock compression must be based on an average ring size less than 4 .

Infrared and Raman spectra obtained at atmospheric pressure on silica glass densified (perhaps by as much as $30 \%$ ) at pressures up to $17 \mathrm{GPa}$ indicate that octahedrally coordinated $\mathrm{Si}$ is not present [Arndt and Stöfler, 1969; Arndt, 1983; Grimsditch, 1984 and similar results have been obtained for $\mathrm{MgSiO}_{3}$ glass held at pressures of several hundred kilobars (Q. Williams and R. Jeanloz, personal communication, 1987). Likewise, Raman and nuclear magnetic remanence (NMR) spectra of albitic glasses quenched from liquids held at $3.5-4.0 \mathrm{GPa}$ do not show any octahedrally coordinated Al [Sharma et al., 1979; Hamilton et al., 1986], though albitic glasses quenched from greater than 6.0 GPa do contain octahedrally coordinated Al based on NMR studies [Ohtani et al., 1985]. The molecular dynamics simulations of Matsui, Kawamura, and coworkers [e.g., Matsui et al,, 1982] are consistent with these spectroscopic results since they suggest that negligible amounts of octahedrally coordinated $\mathrm{Si}$ are present in enstatitic melts until $V / V_{O}$ reaches $0.6-0.7$ and that in anorthitic melt, Al coordinations greater than lour are not observed until $\mathrm{V} / \mathrm{V}_{\mathrm{O}}$ reaches about 0.8 ; substantial compressions are achieved entirely with tetrahedrally coordinated Si and Al by distortion of the tetrahedra and of the linkages between neighboring tetrahedra (i.e., decrease in Si-O-Si angles) and by decreases in the sizes of rings of tetrahedra. These simulations and those of Angell and his coworkers [e.g., Woodcock et al., 1976; Angell et al., 1983, 1986] predict, consistent with with our results, that increases in the average coordination numbers of $\mathrm{Al}$ and $\mathrm{Si}$ are gradual and continuous over pressure intervals of a few tens of gigapascals and that increases in the coordination of $\mathrm{Al}$ occurs at lower pressure than equivalent increases in $\mathrm{Si}$ coordination. One difference between the simulations of
Matsui and his coworkers and those of Angell and his coworkers is that the latter group observes average coordination numbers of $\mathrm{Al}$ and $\mathrm{Si}$ increasing continuously as pressure increases above zero (in apparent conflict with the spectroscopic quench studies discussed above), whereas Matsui's group only detected coordination numbers greater than four for $\mathrm{V} / \mathrm{V}_{\mathrm{O}} \leq \mathbf{0 . 8}$.

The fact that our results on the compression of a $\mathrm{Si}-$ and Al-bearing liquid can, up to $\sim 25 \mathrm{GPa}$, be fit by a single Birch-Murnaghan equation of state with a 1-atm bulk modulus essentially identical to the ultrasonic value strongly suggests to us that the mechanisms of compression over this pressure range are continuous. In other words, if at $1 \mathrm{~atm}$ the coordinations of $\mathrm{Si}$ and $\mathrm{Al}$ are entirely tetrahedral and at $25 \mathrm{GPa}$ they are entirely octahedral, then we expect that the conversion from one coordination state to the other proceeds continuously as pressure increases from $1 \mathrm{~atm}$ to $25 \mathrm{GPa}$. At first glance, this statement would appear to be inconsistent with spectroscopic observations of quenched glasses and molecular dynamics simulations discussed in the preceding paragraph that suggest that $\mathrm{Si}$ and $\mathrm{Al}$ are entirely tetrahedrally coordinated up to relatively high compressions. Consider, however, the compression of a chain of silicate tetrahedra, as illustrated in Figure 12. Starting from a straight chain (Figure 12a), the chain can be continuously compressed by decreasing the $\mathrm{Si}-\mathrm{O}-\mathrm{Si}$ angle and keeping all of the $\mathrm{Si}$ in tetrahedral coordination (Figures 12b-12e). If this accordionlike compression continues far enough, however, the oxygen packing becomes that of a chain of face-shared octahedra (Figure 12f). If the directed bonds characteristic of tetrahedral coordination of $\mathrm{Si}$ or Al persist into this highly compressed state, spectroscopic observations would still conclude that the structure is dominated by tetrahedral coordination, even though the geometry of the packing is dominated by octahedra. We expect, however, that at some point, the cations would begin to form bonds with the oxygens from neighboring tetrahedra. Spectroscopic investigations of the progressively deforming chain would thus show only vibrations characteristic of tetrahedral coordination at low degrees of compression, but at higher pressures these gradually would give way to vibrations indicative of octahedral coordination. Some indications of this type of behavior have been reported recently by Williams and Jeanloz [1987] for compression of $\mathrm{CaAl}_{2} \mathrm{Si}_{2} \mathrm{O}_{8}$ glass above $20 \mathrm{GPa}$ : Note that although the oxygen atoms are in the same positions in Figures 12e and 12f, the positions of the $\mathrm{Si}(\mathrm{Al})$ atoms differ, each having moved through a face of a tetrahedron in the switch from tetrahedral to octahedral bonding environments. This model has recently been further explored by Stolper and Ahrens [1987].

An important aspect of this picture is that the change in oxygen packing from the expanded low-pressure tetrahedral network to a collapsed configuration that can be described in terms of oxygen octahedra is continuous and displacive; it might thus be difficult to preserve octahedrally coordinated states on quenching. In other words, the structure might readily "spring back" into tetrahedral coordination as pressure is released. There are thus two factors that can account for the fact that octahedral coordination of $\mathrm{Si}$ has not been observed at room pressure in glasses quenched from the high pressures required to permanently densify a glass. The first factor is the likely difficulty of pressure quenching a continuous transformation of this sort. The second is that only after the chains are substantially compressed, and then only when the $\mathrm{Si}(\mathrm{Al})$ begin to form bonds with the oxygen atoms of the adjacent tetrahedra, will spectroscopic observations detect this continuous transformation. Spectroscopic studies conducted in situ on samples at high pressures should, at high enough compressions, eventually detect octahedral coordination growing in at the expense of tetrahedral coordination, and the transformation is expected to be continuous and reversible.

We note that there are many potentially important aspects of the accordionlike collapse illustrated in Figure 12 that we have not considered. For example, (1) the bonding of the silicate chain to other cations (e.g., $\mathrm{Mg}, \mathrm{Ca}$ ) and 


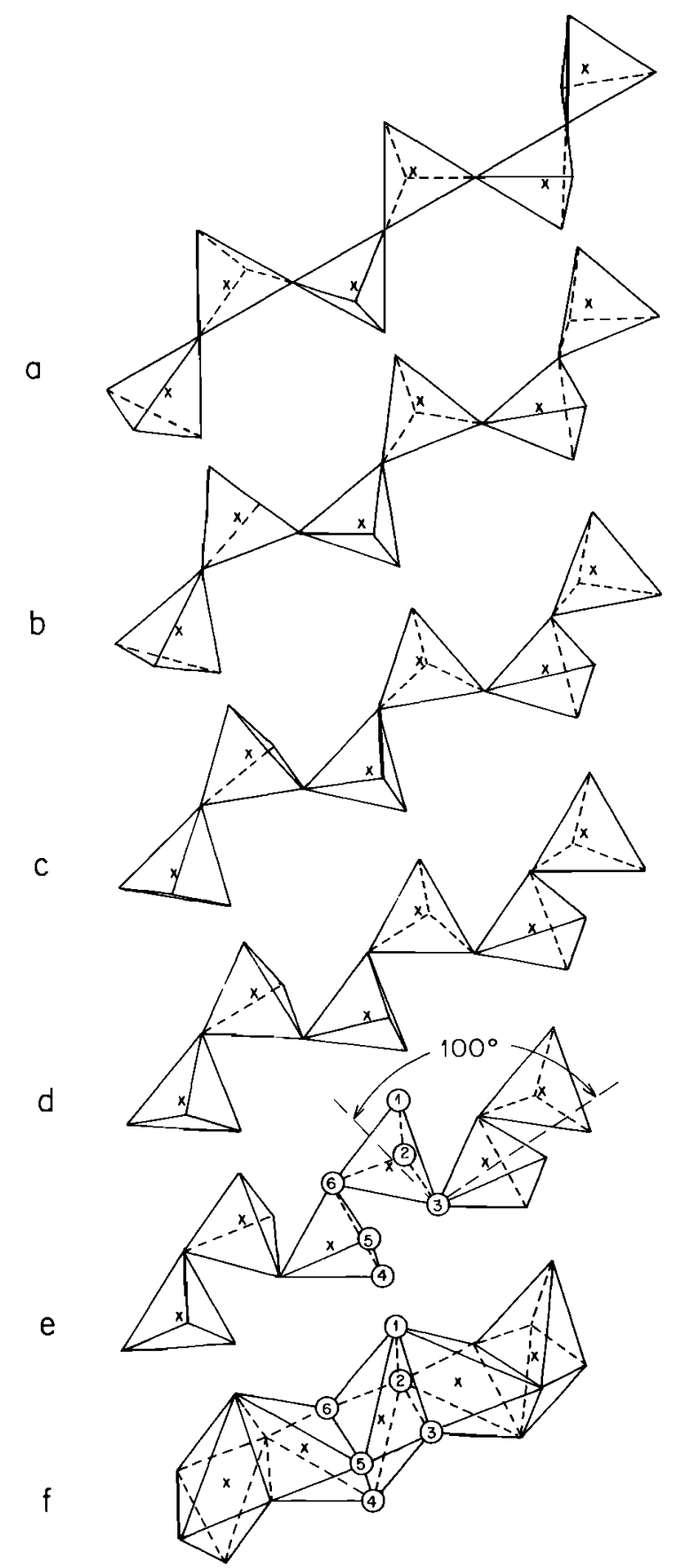

Fig. 12. Progressive distortion of a chain of $\mathrm{SiO}_{4}$ tetrahedra upon compression. Dashed lines are "hidden" edges of polyhedra. (a) Si-O-S1 angle $=180^{\circ}$ (b) Si-O-Si angle $=160^{\circ}$. (c) Si-O-Si angle $=140^{\circ}$. (d) $\mathrm{Si}-\mathrm{O}-\mathrm{Si}$ angle $=$ $120^{\circ}$. (e) Si-O-Sı angle $=100^{\circ}$. (f) Same as chain in Figure 12e, except coordination polyhedra redrawn as a chain of face-shared octahedra. The numbered circles show the positions of the same oxygen atoms in Figures 12e and 12r. Si positions (crosses) have been moved to be near the centers of the octahedra in Figure 12f. Because of the finite length of the chain in Figure 12e, one $\mathrm{Si}$ and one $\mathrm{O}$ (at the lower left) are not reproduced in Figure $12 \mathrm{f}$ (after Stolper and Ahrens [1987]).

how these bonds must bend and break as the chain collapses have not been taken into account. Similarly, we have not considered here how this process could apply to silicate polymers other than chains. (2) The energetics of face-shared octahedra have not been considered. This kind of structure violates Pauling's [1960, p. 559] second rule and has not been observed so far as we know in crystals with octahedrally coordinated $\mathrm{Si}$ or Al. However, as shown in Stolper and Ahrens [1987], networks of edge-shared oxygen octahedra and pentahedra can also be generated by extreme distortions of tetrahedral polymers and networks. (3) Chains such as those shown in Figure 12 would probably not collapse homogeneously. Thus, particularly at intermediate degrees of compression, a wide range of local, probably highly distorted 4-, 5-, and 6-coordinated environments can be expected, rather than the orderly collapse implied by Figure 12 .

We emphasize that Figure 12 and its description are highly idealized. We want only to llustrate that the kinds of distortions in the tetrahedral aluminosilicate network (e.g., decreases in Si-O-Si angles) that are believed to dominate melt and glass compressions at low (0-3 GPa) pressures can lead continuously to higher coordination numbers. The transformation to higher coordinations may, in addition, be difficult to quench and to detect spectroscopically in situ at high pressures unless the compression is substantial. Although we think that compression of aluminosilicate polymers via this accordionlike distortion would result in densities consistent with our results, we feel that further consideration of this specific mechanism should await the results of spectroscopic studies of melts and glasses at high pressures.

\section{Conclusions}

We have carried out shock wave experiments on a molten silicate to determine its density at elevated pressure. The basalt analog, $\mathrm{An}_{0}{ }_{36} \mathrm{Di}_{0.64}$, undergoes relatively smooth compression to $\sim 25 \mathrm{GPa}$; above this pressure a marked lowering of the compressibility occurs. A Birch-Murnaghan isentrope calculated from the Hugoniot data up to $25 \mathrm{GPa}$ has a 1 -atm bulk modulus $K_{0 S}$ of $24.2 \mathrm{GPa}$ and a pressure derivative $\mathrm{K}^{\prime}$ of $\mathbf{4 . 8 5}$. This 1 -atm bulk modulus is similar to the relaxed value calculated from the data of Rivers [1985] on ultrasonic velocities in melts. This simllarity suggests that the shock wave experiments probe relaxed structural states of the melt.

Although calculated shock temperatures may lie below those expected for the liquidus of this composition over the pressure range of these experiments, crystallization is not thought to have occurred. Rather, it is believed that continuous compression of the melt structure occurs with increases in pressure until a dense, high-pressure structure is reached. Achievement of this high-pressure structure could explain the significant stiffening of this material at pressures in excess of $25 \mathrm{GPa}$ The expected density of a melt structure in which $\mathrm{Al}$ and $\mathrm{Si}$ are nearly entirely in octahedral coordination is similar to the values measured in our highest-pressure experıments; although our data are consistent with major $\mathrm{Al}$ and $\mathrm{Si}$ coordination changes occurring during compression of melts to high pressures, we cannot discriminate between this and other possible structural arrangements, including entirely tetrahedral ones, that might achieve similar densities at high pressures.

Acknowledgments We appreciate the excellent technical assistance of E. Gelle, W Ginn, C. Manning, and M. Long in building and carrying out these experiments. E. Bus and $W$ Kershaw prepared many of the samples. We appreciate the use of the $10-\mathrm{kW}$ RF heater provided by $\mathrm{L}$. T. Silver. This work was supported under National Science Foundation grants EAR80-18819 and EAR84-07784. S.M.R. gratefully acknowledges the support of an IBM Pre Doctoral Fellowship during 1984/1985. Discussions and reviews by C A. Angell, D. L. Anderson, B. H. Hager, P. Gaskell, R. Jeanloz, G. Miller, and Q. Williams have been very helpful. Division of Geological and Planetary Sciences contribution 4351, California Institute of Technology, Pasadena, California. 


\section{References}

Ahrens, T. J., Shock wave techniques for geophysics and planetary physics, in Methods of Experimental Physics, edited by C Sammis and T. L. Henyey, Vol. 24, Part A, pp. 185-235, Academic, Orlando, Fla., 1987.

Ahrens, T. J., D. L. Anderson, and A. E. Ringwood, Equation of state and crystal structure of high-pressure phases of shocked silicates and oxides, Rev. Geophys.., 7, 667-707, 1969.

Ahrens, T. J., J H. Lower, and P. L. Lagus, Equation of state of forsterite, J Geophys. Res, 76, 514-528, 1971.

Ahrens, T. J., I. Jackson, and R. Jeanloz, Shock compression and adiabatic release of a titaniferous mare basalt, Proc. Lunar Sci. Conf., 8th, 3437-3455, 1977.

Al'tshuler, L. V., Use of shock waves in high-pressure physics, Sov. Phys. Usp., Engl. Transl., 85, 52-91, 1965.

Anderson, O L., E Schreiber, and R. C. Liebermann, Some elastic constant data on minerals relevant to geophysics, Rev. Geophys., 6, 491-524, 1968.

Angell, C. A., P. A. Cheeseman, and S. Tamaddon, Pressure enhancement of ion mobilities in liquid silicates from computer simulation studies to 800 kılobars, Science, 218, 885-887, 1982.

Angell, C A., P. Cheeseman, and S. Tamaddon, Water-like transport property anomalies in lıquid silicates investigated at high $\mathrm{T}$ and $\mathrm{P}$ by computer simulation techniques, Bull. Mineral., 106, 87-97, 1983.

Angell C. A., P. A. Cheeseman, and R. R. Kadiyala, Diffusivity and thermodynamic properties of diopside and jadeite melts by computer simulation studies, Chem. Geol., 62, 85-95, 1987.

Arndt, J., Densification of glasses of the system $\mathrm{TiO}_{2}-\mathrm{SiO}_{2}$ by very high static pressures, Phys. Chem. Glasses, 24 , 104-110, 1983.

Arndt, J. and D. Stöfler, Anomalous changes un some properties of silica glass densified at very high pressures, Phys. Chem. Glasses, 10, 117-124, 1969

Boettcher, A. L., C. W. Burnham, K. E. Windom, and S. R. Bohlen, Liquids, glasses, and the melting of silicates to high pressures, J. Geol, $\underline{90}, 127-138,1982$

Boettcher, A. L., Q. Guo, S. Bohlen, and B. Hanson, MeltIng in feldspar-bearing systems to high pressures and the structure of aluminosilicate liquids, Geology, 12, 202-204, 1984

Boslough, M. B , S. M Rigden, and T. J. Ahrens, Hugoniot equations of state of anorthite glass and lunar anorthosite, Geophys. J R. Astron. Soc. 84, 455-473, 1986.

Bottinga, Y., On the isothermal compressibility of silicate liquids at high pressure, Earth Planet. Sci. Lett., $\underline{74}$, $350-360,1985$

Bottinga, Y., and D. F. Weill, Densities of silicate liquid systems calculated from partial molar volumes of oxide components, Am. J. Sci., 269, 169-182, 1970

Bottinga, Y., and D. F. Weill, The viscosity of magmatic silicate liquids: A model for calculation, Am. J Sci. $272,438-475,1972$.

Bottinga, Y., D. Well, and P Richet, Density calculations for silicate liquids, I, Revised method for aluminosilicate compositions, Geochim. Cosmochim. Acta, 46, 909-919, 1982.

Bowen, N. L., The crystallization of haplobasaltic, haplodioritic and related magmas, Am. J. Sci., 40, 161-185, 1915.

Brearley, M., J. E. Dickinson, Jr., and C. M. Scarfe, Pressure dependence of melt viscosities on the join diopside-albite, Geochim. Cosmochim Acta, 50, 2563$2570,1986$.

Cranmer, D., R. Salomaa, H Yinnon, and D. R. Uhlmann, Barrier to crystal nucleation in anorthite, J. Non Crvst. Solids, $\underline{45}, 127-136,1981$.

Davies, G. F., Equations of state and phase equilibria of stishovite and a coesite-like phase from shock-wave and other data, J. Geophys. Res., 77, 4920-4933, 1972.

Fiori, C., and R. A. B Devine, Evidence for a wide continuum of polymorphs in a-SiO 2 Phys. Rev, B, $\underline{33}, 2972$ $2974,1986$.

Fujii, T., and I. Kushiro, Density, viscosity and compressi- bility of basaltic liquid at high pressures, Year Book Carnegie Inst. Washington, $\underline{76}$, 419-424, 1977 .

Goldsmith, J. R., The meltıng and breakdown reactions of anorthite at high pressures and temperatures, Am. Mineral. $\underline{65}, 272-284,1980$.

Goto, T, G. R. Rossman, and T. J. Ahrens, Absorption spectroscopy of solids under shock compression, in Proceedings of 6th AIRAPT International High Pressure Conference. High Pressure Science and Technology Vol. II, edited by K. D. Tımmerhaus and M. S. Barker, pp. 895-904, Plenum, New York, 1979.

Grimsditch, M., Polymorphism in amorphous $\mathrm{SiO}_{2}$, Phys. Rev. Lett., 52, 2379-2381, 1984.

Hamilton, D. L., W. Chesworth, G. Kennedy, and C. Fyfe The absence of 6-fold coordinated $\mathrm{Al}$ in jadeite melt near the jadeite liquidus, Geochim Cosmochım Acta, $50,123-124,1986$.

Jackson, I, and T. J Ahrens, Shock wave compression of single-crystal forsterite, I. Geophys. Res, 4, 3039$3048,1979$.

Jeanloz, R., and T J. Ahrens, Release adiabat measurements on minerals The effect of viscosity, J. Geophvs Res. 84, 7545-7547, 1979.

Jeanloz, R., and T. J. Ahrens, Equations of state of $\mathrm{FeO}$ and $\mathrm{CaO}$, Geophys. J. R Astron. Soc., 62, 505-528, 1980a.

Jeanloz, R., and T.J. Ahrens, Anorthite: Thermal equation of state to high pressures, Geophys. J. Roy Astron. Soc., 62, 529-549, $1980 \mathrm{~b}$.

Jeanloz, R., and D. Heinz, Experiments at high temperature and pressure: Laser heating through the diamond cell, J. Phys., C, 4 45, 8.83-8.92, 1984

Kushiro, I., Viscosity and structural changes of albite $\left(\mathrm{NaAlSi}_{3} \mathrm{O}_{8}\right)$ melt at high pressures, Earth Planet. Sci. Lett, $41,87-90,1978$

Kushiro, I., Viscosity, density, and structure of sllicate melts at high pressures, and their petrological applications, in Physics of Magmatic Processes, edited by R B. Hargraves, pp. 93-120, Princeton University Press, Princeton, N.J., 1980.

Kushiro, I., Changes in viscosity with pressure of melts in the system $\mathrm{CaO}-\mathrm{Al}_{2} \mathrm{O}_{3}-\mathrm{SiO}_{2}$, Year Book Carnegie Inst. Washington, 80,339-341, 1981.

Liu, L-G., The system enstatite-wollastonite at high pressures and temperatures with emphasis on diopside, Phys. Earth Planet. Inter., 19, P15-P18, 1979

Lyzenga, G. A., T. J. Ahrens, and A. C. Mitchell, Shock temperatures of $\mathrm{SiO}_{2}$ and their geophysical implications, J. Geophys. Res., 88, 2431-2444, 1982

Marsh, S.P., LASL Shock Hugoniot Data, 658 pp., University of California Press, Berkeley, 1980.

Matsui, Y., and K. Kawamura, Instantaneous structure of an $\mathrm{MgSiO}_{3}$ melt by molecular dynamics, Nature, $\underline{285}$ 648-649, 1980.

Matsui, Y., and K. Kawamura, Computer simulation of structures of sllicate melts and glasses, in Materials Science of the Earth's Interior, edited by I. Sunagawa, pp 3-23, Terra Scientific, Tokyo, 1984

Matsui, Y., K. Kawamura, and Y. Syono, Molecular dynamics calculations applied to silıcate systems: Molten and vitreous $\mathrm{MgSiO}_{3}$ and $\mathrm{Mg}_{2} \mathrm{SlO}_{4}$ under low and high pressures, in High Pressure Research in Geophysics, edited by S. Akimoto and M. H. Manghnani, pp 511-524, Center for Academic Publications, Tokyo, 1982 .

McQueen, R. G., S. P. Marsh, and J. N. Fritz, Hugoniot equation of state of twelve rocks, J. Geophys. Res., $\underline{72}$, 4999-5036, 1967.

McQueen, R. G., S. P. Marsh, J. W. Taylor, J. N. Fritz, and $W$. J. Carter, The equation of state of solids from shock wave studies, in High Pressure Impact Phenomena, edited by R. Kinslow, pp. 293-417, Academic, Orlando, Fla., 1970

Melson, W. G., and G Thompson, Petrology of a transform lault zone and adjacent ridge segments, Phulos. Trans. R. Soc. London Ser., A, 268, 423-441, 1971. 
Mo, X., I.S.E. Carmichael, M. Rivers, and J. Stebbins, The partial molar volume of $\mathrm{Fe}_{2} \mathrm{O}_{3}$ in multicomponent silicate liquids and the pressure dependence of oxygen fugacity in magmas, Mineral. Mag. 45, 237-245, 1982

Nelson, S. A., and I.S.E. Carmichael, Partial molar volumes of oxide components in silicate liquids, Contrib. Mineral. Petrol., 71, 117-124, 1979

Nisbet, E. G., and D. Walker, Komatiites and the structure of the Archaean mantle, Earth Planet. Sci. Lett. 60 105-113, 1982.

Ohtani, E., Generation of komatiite magma and gravitational differentiation in the deep upper mantle, Earth Planet. Sci. Lett., 67, 261-272, 1984.

Ohtani, E., and M. Kumazawa, Melting of forsterite $\mathrm{Mg}_{2} \mathrm{SiO}_{4}$ up to $15 \mathrm{GPa}$, Phys. Earth Planet. Inter. 27 $32-38,1981$

Ohtani, E., F Taulelle, and C. A. Angell, $\mathrm{Al}^{3+}$ coordination changes in liquid aluminosilicates under pressure, Nature, 314, 78-81, 1985

Pauling, L, The Nature of the Chemical Bond, 644 pp., Cornell University Press, Ithaca, N.Y., 1960.

Presnall, D. C., S. A. Dixon, J. R. Dixon, T. H. O'Donnell, N. L. Brenner, R. L. Schrock, and D. W. Dycus, Liquidus phase relations on the join diopside-forsteriteanorthite from $1 \mathrm{~atm}$ to $20 \mathrm{kbar}$ : Their bearing on the generation and crystallization of basaltic magma, Contrib. Mineral. Petrol., 66, 203-220, 1978.

Rai, C S., M H. Manghnani, and K. W. Katahara, Ultrasonic studies on a basalt melt, Geophys. Res. Lett., 8 $1215-1218,1981$

Rice, M. H, R. G. McQueen, and J. M. Walsh, Compression of solids using strong shock waves, in Solid State Physics, Vol. 6, edited by F. Seitz and D. Turnbull, pp. 1-63, Academic, Orlando, Fla., 1958.

Richet, P., R. A. Roble, and B. S. Hemingway, Low temperature heat capacity of diopside glass $\left(\mathrm{CaMgSi}_{2} \mathrm{O}_{6}\right)$ : A calorimetric test of the configurational entropy theory applied to the viscosity of liquid silicates, Geochim Cosmochim. Acta, 50, 1521-1533, 1986.

Rigden, S. M., T. J. Ahrens, and E. M. Stolper, Densities of liquid silicates at high pressures. Science, 226, 1071$1074,1984$.

Rivers, M., Ultrasonic studies of silicate liquids, Ph.D. dissertation, Univ. of Calif., Berkeley, 1985.

Robie, R A., B. S. Hemingway, and J. R. Fisher, Thermodynamic properties of minerals and related substances at $298.15 \mathrm{~K}$ and 1 bar ( $10^{5}$ pascals) pressure and higher temperatures, U S. Geol. Survey Bull., \#1452, 456 pp., 1978.

Rosenhauer, M., R. M. Martens, H. Büttner, and W. Weinberg, Thermodynamic characterization of the glass transformation interval from rate cooling experiments: System $\mathrm{CaAl}_{2} \mathrm{Si}_{2} \mathrm{O}_{8}-\mathrm{CaMgSl}_{2} \mathrm{O}_{6}$ and $\mathrm{NaAlSi}_{3} \mathrm{O}_{8^{-}}$ $\mathrm{CaMgSi}_{2} \mathrm{O}_{6}$ (abstract), presented at Colloquium on Physique et Chimie des Liquides Silicatés, Association Européenne de Géochimie, Carry-le-Rouet, France, 2628, November 1985.

Ruoff, A.L., Linear shock-velocity-particle-velocity relationship, J. Appl. Phvs, 38, 4976-4980, 1967.

Scarfe, C. M., B. O. Mysen, and D. Virgo, Changes in viscosity and density of melts of sodium disilicate, sodium metasilicate and diopside composition with pressure, Year Book Carnegie Inst. Washington, $547-551,1979$.

Slarma, S. K., D Virgo, and B. O. Mysen, Raman study of the coordination of aluminum in jadeite melt as a function of pressure, Am. Mineral., 64, 779-787, 1979.

Sharpe, R., T. N. Irvine, B. O. Mysen, and R. M. Hazen, Density and viscosity of melts of Bushveld Chilled Margin rocks, Year Book Carnegie Inst. Washington, 82, $300-305,1983$.

Stebbins, J. R., I. S. E. Carmichael, and L. K. Moret, Heat capacities and entropies of sllicate liquids and glasses, Contrib. Mineral. Petrol., 86, 131-148, 1984.

Stolper, E. M., and T. J. Ahrens, On the nature of pressure-induced coordination changes in silicate melts and glasses, Geophys. Res. Lett., in press, 1987.

Stolper, E. M., D. Walker, B. H. Hager, and J. F. Hays, Melt segregation from partially molten source regions: The importance of melt density and source region size, J Geophys. Res., 86, 6261-6271, 1981.

Svendsen, B., and T. J. Ahrens, Dynamic compression of diopside and salite to $200 \mathrm{GPa}$, Geophys. Res. Lett., 10 , 501-504, 1983.

Touloukian, Y. S., R. K. Kirby, R. E. Taylor, and P.D. Desai, Thermal Expansion of Metallic Elements and Allovs, Plenum, New York, 1970.

Uhlmann, D. R., and L. C. Klein, Crystallization kinetics, viscous flow and thermal histories of lunar breccias 15286 and 15498, Proc.Lunar Sci. Conf. 7 th, 2529$2541,1976$.

Uhlmann, D R., P. I. K. Onoroto, and G. W. Sheer, A simplified model for glass formation, Proc. Lunar Planet. Sci. Conf, 10th, 375-381, 1979.

Uhlmann, D. R., H. Yinnon, and C. Y. Fang, Simplified model evaluation of cooling rates for glass-containing lunar compositions, Proc. Lunar Planet. Sci. Conf., 12B, 281-288, 1981.

Vassiliou, M. S., and T. J. Ahrens, Hugoniot equation of state of periclase above $100 \mathrm{GPa}$, Geophys. Res. Lett. 8, 729-732, 1981.

Wackerle, J., Shock-wave compression of quartz, J. Appl. Plivs., 33, 922-937, 1962.

Waff, H. S., Pressure-induced coordination changes in magmatic liquids, Geophrs. Res. Lett., 2, 193-196, 1975

Weidner, D. J., J. D. Bass, A. E. Ringwood, and W. Sinclair, The single-crystal elastic moduli of stishovite, J. Geophys. Res., 87, 4740-4746, 1982.

Weill, D. F., R. Hon, and A. Navrotsky, The igneous system $\mathrm{CaMgSi}_{2} \mathrm{O}_{6}-\mathrm{CaAl}_{2} \mathrm{Si}_{2} \mathrm{O}_{8}-\mathrm{NaAlSi}_{3} \mathrm{O}_{8}$ : Variations on a classic theme by Bowen, in Physics of Magmatic Processes, edited by R. B. Hargraves, pp. 49-92, Princeton University Press, Princeton, N.J., 1980.

Williams, Q., and Jeanloz, R., High pressure coordination changes in silicates: Is glassy octahedral silicon unquenchable?, paper presented at 1987 Spring Meeting, Mater. Res. Soc., Anaheim, Ca., 1987.

Woodcock, L. V., C. A. Angell, and P. Cheeseman, Molecular dynamics studies of the vitreous state: Simple ionic systems and silica, $\underline{\mathrm{J} \text {. Chem. Phvs, }} \underline{65}, 1565-1577,1976$.

T. J. Ahrens and E. M. Stolper, California Institute of Technology, Pasadena, CA 91125

S. M. Rigden, Research School of Earth Sciences, Australian National University, Canberra ACT 2600, Australia.

(Received September 15, 1986; revised June 8, 1987 accepted August 6, 1987.) 